\title{
Review Article \\ PET Radiopharmaceuticals for Imaging Integrin Expression: Tracers in Clinical Studies and Recent Developments
}

\author{
Roland Haubner, ${ }^{1}$ Simone Maschauer, ${ }^{2}$ and Olaf Prante ${ }^{2}$ \\ ${ }^{1}$ Department of Nuclear Medicine, Innsbruck Medical University, Anichstraße 35, 6020 Innsbruck, Austria \\ ${ }^{2}$ Molecular Imaging and Radiochemistry, Department of Nuclear Medicine, Friedrich-Alexander University, \\ Schwabachanlage 6, 91054 Erlangen, Germany
}

Correspondence should be addressed to Roland Haubner; roland.haubner@i-med.ac.at

Received 25 March 2014; Accepted 29 April 2014; Published 11 June 2014

Academic Editor: Patrick Riss

Copyright (C) 2014 Roland Haubner et al. This is an open access article distributed under the Creative Commons Attribution License, which permits unrestricted use, distribution, and reproduction in any medium, provided the original work is properly cited.

\begin{abstract}
Noninvasive determination of integrin expression has become an interesting approach in nuclear medicine. Since the discovery of the first ${ }^{18} \mathrm{~F}$-labeled cyclic RGD peptide as radiotracer for imaging integrin $\alpha_{v} \beta_{3}$ expression in vivo, there have been carried out enormous efforts to develop RGD peptides for PET imaging. Moreover, in recent years, additional integrins, including $\alpha_{5} \beta_{1}$ and $\alpha_{v} \beta_{6}$, came into the focus of pharmaceutical radiochemistry. This review will discuss the tracers already evaluated in clinical trials and summarize the preliminary outcome. It will also give an overview on recent developments to further optimize the firstgeneration compounds such as $\left[{ }^{18} \mathrm{~F}\right]$ Galacto-RGD. This includes recently developed ${ }^{18} \mathrm{~F}$-labeling strategies and also new approaches in ${ }^{68} \mathrm{Ga}$-complex chemistry. Furthermore, the approaches to develop radiopharmaceuticals targeting integrin $\alpha_{5} \beta_{1}$ and $\alpha_{v} \beta_{6}$ will be summarized and discussed.
\end{abstract}

\section{Introduction}

Integrins are heterodimeric glycoproteins consisting of an $\alpha$ - and $\beta$-subunit. There are 24 different combinations of the eight $\beta$-units and the eighteen $\alpha$-units known. The integrins mediate cell-cell and cell-matrix interactions and transduce signals across the plasma membrane via insightout and outside-in signaling [1]. Some of the integrins play an important role during migration of endothelial as well as tumor cells during tumor-induced angiogenesis and tumor metastasis. Angiogenesis, the formation of new blood vessels out of the preexisting vasculature, is a critical step in the development and dissemination of many human tumors. A variety of therapeutic strategies in oncology are focused on the inhibition of tumor-induced angiogenesis [2-4]. This includes approaches to inhibit VEGF, MMP, or integrin interactions. Concerning the integrins, most attention has been paid to the role of integrin $\alpha_{v} \beta_{3}$ and $\alpha_{v} \beta_{5}$ as they are prominent on proliferating vascular endothelial cells [5].

Thus, one of the most prominent target structures used for the development of radiopharmaceuticals for imaging angiogenesis is the integrin $\alpha_{v} \beta_{3}$ [6]. It has been shown that this integrin is involved in endothelial cell/matrix interaction during tumor-induced formation of new vessels as well as in mediation of tumor cell migration during invasion and extravasation [7]. A series of studies using a variety of different radiopharmaceuticals have already demonstrated that noninvasive determination of $\alpha_{v} \beta_{3}$ expression is feasible (for review, see $[6,8]$ ).

In contrast to the data found in a variety of inhibition studies, which suggest a critical role for $\alpha_{v} \beta_{3}$ in angiogenesis, genetic studies indicate that the integrin $\alpha_{v} \beta_{3}$ is not required for angiogenesis [5]. An explanation for this discrepancy could be findings that animals lacking $\alpha_{v} \beta_{3}$ develop compensatory changes in VEGF signaling, which permit angiogenesis to occur during embryogenesis [9]. Anyway, genetic ablation of the integrin $\alpha_{5} \beta_{1}$, the major fibronectinbinding integrin, leads to severe vascular abnormalities [10] indicating that this integrin may play an even more important role as the integrin $\alpha_{v} \beta_{3}$ in neovascularization. Additionally, this integrin is upregulated in tumor blood vessels and plays a role in tumor angiogenesis and tumor growth [11, 12]. 
Thus, recently this integrin became another target structure in the development of radiopharmaceuticals for imaging angiogenesis.

A third class of tracer developed for the noninvasive determination of integrin expression focus on the integrin $\alpha_{v} \beta_{6}$. This integrin is unique in that it is exclusively expressed on epithelial cells [13]. It is highly upregulated during development of lung, skin, and kidney epithelia but its expression is low in healthy adult epithelia [14]. Elevated expression in adults is found only during wound healing [15]. It is found to regulate epithelial remodeling during development and tissue repair. Thus, it became an interesting target in tracer development because integrin $\alpha_{v} \beta_{6}$ is also found to be highly expressed on a variety of tumors including carcinoma of the breast, lung, colon, stomach, and oral and skin squamous cell carcinoma [13] and is associated with a more aggressive disease outcome [16].

There are already a variety of reviews dealing with the development of tracer targeting the integrins $\alpha_{v} \beta_{3} / \alpha_{v} \beta_{5}[6$, $8,25-27]$. On the one hand, this review will focus on compounds which are already in clinical studies and, on the other hand, highlight most recent aspects of the preclinical development of tracer targeting these integrins. Moreover, it will summarize the developments concerning radiopharmaceuticals targeting the integrins, $\alpha_{5} \beta_{1}$ and $\alpha_{v} \beta_{6}$, which came most recently in the focus for PET tracer development (Table 1).

\section{Tracer Targeting Integrin $\alpha_{v} \beta_{3} / \alpha_{v} \beta_{5}$}

\subsection{Tracers Already in Clinical Studies}

2.1.1. $\left[{ }^{18}\right.$ F]Galacto-RGD. The first target structure used for the development of radiopharmaceuticals was the integrin $\alpha_{v} \beta_{3}$ [46]. Among the great variety of compounds introduced meanwhile, only a small set entered clinical studies. The first compound studied in patients was $\left[{ }^{18} \mathrm{~F}\right]$ Galacto-RGD. This compound was developed based on an optimization strategy introducing sugar moieties to improve the pharmacokinetics $[28,47]$. Initial clinical studies showed that the tracer was well tolerated with no severe side effects [48-50]. The effective dose calculated from an i.v. injection of $\left[{ }^{18} \mathrm{~F}\right]$ Galacto-RGD was found to be approximately $0.02 \mathrm{mSv} / \mathrm{MBq}$ [50], being in the range of a routine $\left[{ }^{18} \mathrm{~F}\right] \mathrm{FDG}-\mathrm{PET}$ scan [51]. The tracer was rapidly cleared predominately via kidneys, resulting in good tumor/background ratios. The highest background uptake was found in kidneys, liver, spleen, and intestine. Tumor uptake showed high variability and standard uptake values (SUV) ranged from 1.2 to 10 . An additional study including 19 patients compared $\left[{ }^{18} \mathrm{~F}\right]$ Galacto-RGD uptake in the lesions with immunohistochemical staining after tumor resection using angiogenesis markers (Figure 1) [17, 49].

A good correlation between tracer uptake and $\alpha_{v} \beta_{3}$ expression as well as microvessel density was found. In further investigations, the detection rate of a variety of different malignant lesions was studied including sarcoma, melanoma, renal cell cancer, squamous cell carcinoma of the head and neck, breast cancer, and glioblastoma multiforme
[52-54]. In general, detection of the primary tumor was high $(80 \%-100 \%)$ with a lower detection rate for lymph nodes and distant metastases. It has to be mentioned that the different studies also revealed that chronic inflammatory lesions like villonodular synovitis can also show significant uptake of $\left[{ }^{18} \mathrm{~F}\right.$ ] Galacto-RGD [17], raising the same problem as with $\left[{ }^{18} \mathrm{~F}\right]$ FDG that the tracer does not clearly differentiate between benign and malignant lesions. All the clinical as well as the preclinical data (which are not discussed here) have demonstrated that specific imaging of integrin $\alpha_{v} \beta_{3}$ expression is feasible using $\left[{ }^{18} \mathrm{~F}\right]$ Galacto-RGD and PET; however, it has to be kept in mind that this receptor is not only expressed on endothelial cells during neovascularization but can also be present on the tumor cells themselves. Static PET imaging cannot distinguish the origin of the signal; thus, solely assessing angiogenesis is only possible if the tumor cells do not express the receptor.

Integrin $\alpha_{v} \beta_{3}$ is also expressed by macrophages and angiogenic endothelial cells in atherosclerotic lesions $[55,56]$. Based on this, Beer et al. studied the potential of $\left[{ }^{18} \mathrm{~F}\right]$ GalactoRGD as a probe for imaging plaque inflammation and plaque vulnerability [57]. The pilot study including 10 patients with high-grade carotid artery stenosis scheduled for carotid endarterectomy revealed specific tracer accumulation in atherosclerotic carotid plagues and correlation of the tracer uptake with $\alpha_{v} \beta_{3}$ expression analyzed by immunohistochemical staining of the surgical specimen. Based on the promising initial results it was concluded that larger prospective studies have to be carried out to fully evaluate the potential of molecular imaging of integrin $\alpha_{v} \beta_{3}$ expression for the assessment of plaque inflammation in patients.

2.1.2. $\left[{ }^{18}\right.$ F]Fluciclatide. Another integrin $\alpha_{v} \beta_{3} / \alpha_{v} \beta_{5}$ targeting PET radiopharmaceutical, which has already been studied in patients, is $\left[{ }^{18} \mathrm{~F}\right]$ Fluciclatide. Similar to $\left[{ }^{18} \mathrm{~F}\right]$ GalactoRGD, this peptide derivative includes the RGD sequence as binding motif, but in contrast to the backbone cyclization found in $\left[{ }^{18} \mathrm{~F}\right]$ Galacto-RGD this compound is cyclized via a thioether and a disulfide bridge. As a pharmacokinetic modifier, polyethylene glycol (PEG), instead of the sugar moiety and for radiolabeling an aminooxy function, was introduced. The labeling with ${ }^{18} \mathrm{~F}$ was carried out using 4$\left[{ }^{18} \mathrm{~F}\right]$ fluorobenzaldehyde. This approach using the chemoselective oxime formation for labeling clearly reduced the synthesis time of this radiotracer compared to $\left[{ }^{18} \mathrm{~F}\right]$ GalactoRGD and made the clinical routine production more feasible. In contrast to Galacto-RGD, which belongs to the family of tracer based on the cyclic pentapeptide $\mathrm{c}$ (RGDfV), Fluciclatide shows higher binding affinity for integrin $\alpha_{v} \beta_{5}$ than for integrin $\alpha_{v} \beta_{3}$ [18].

In a study including 7 breast cancer patients it could be shown that all lesions found by CT could also be detected by $\left[{ }^{18} \mathrm{~F}\right]$ Fluciclatide PET (Figure 2). In analogy to $\left[{ }^{18} \mathrm{~F}\right]$ Galacto$\mathrm{RGD}$, a great variance in tracer uptake in the lesions was found with SUVs ranging from 2.0 to 40.0 [18]. Interestingly, metastases in the liver have been identified as regions of deficit uptake, because of the high background activity in 


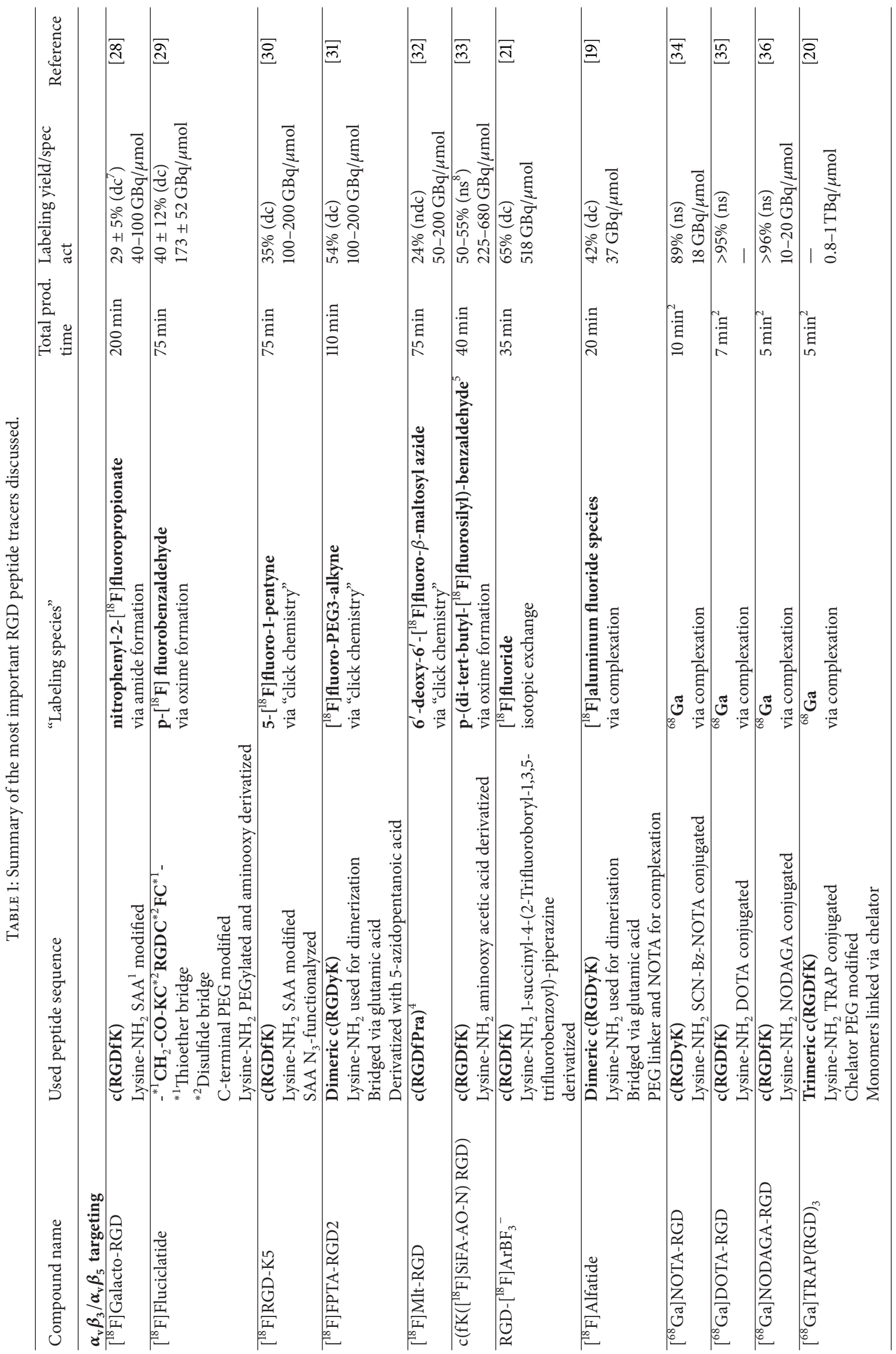




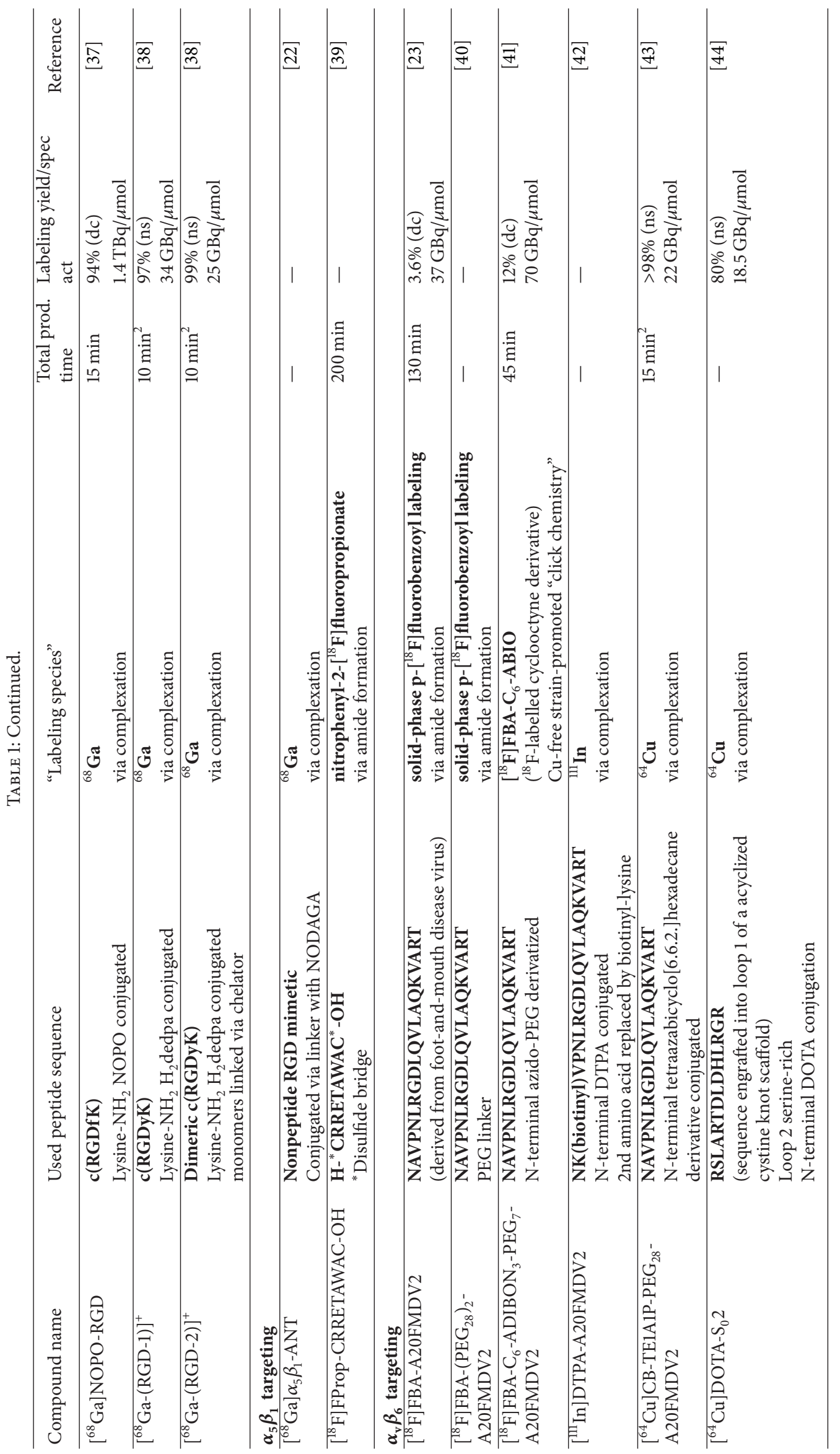




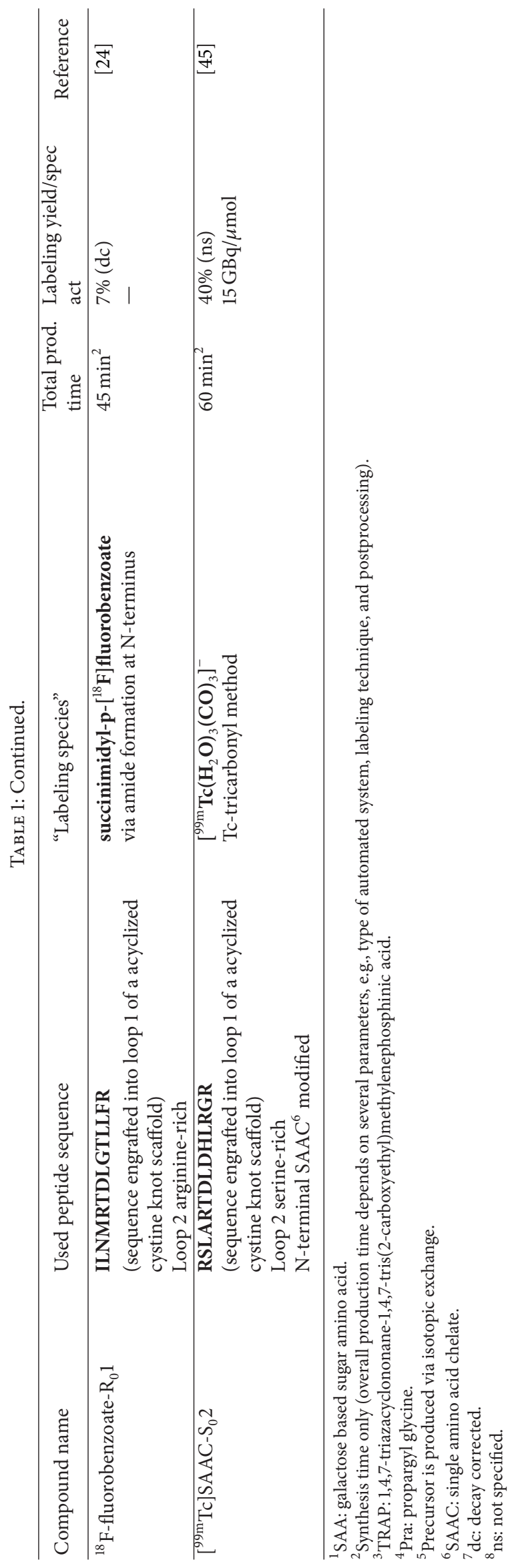



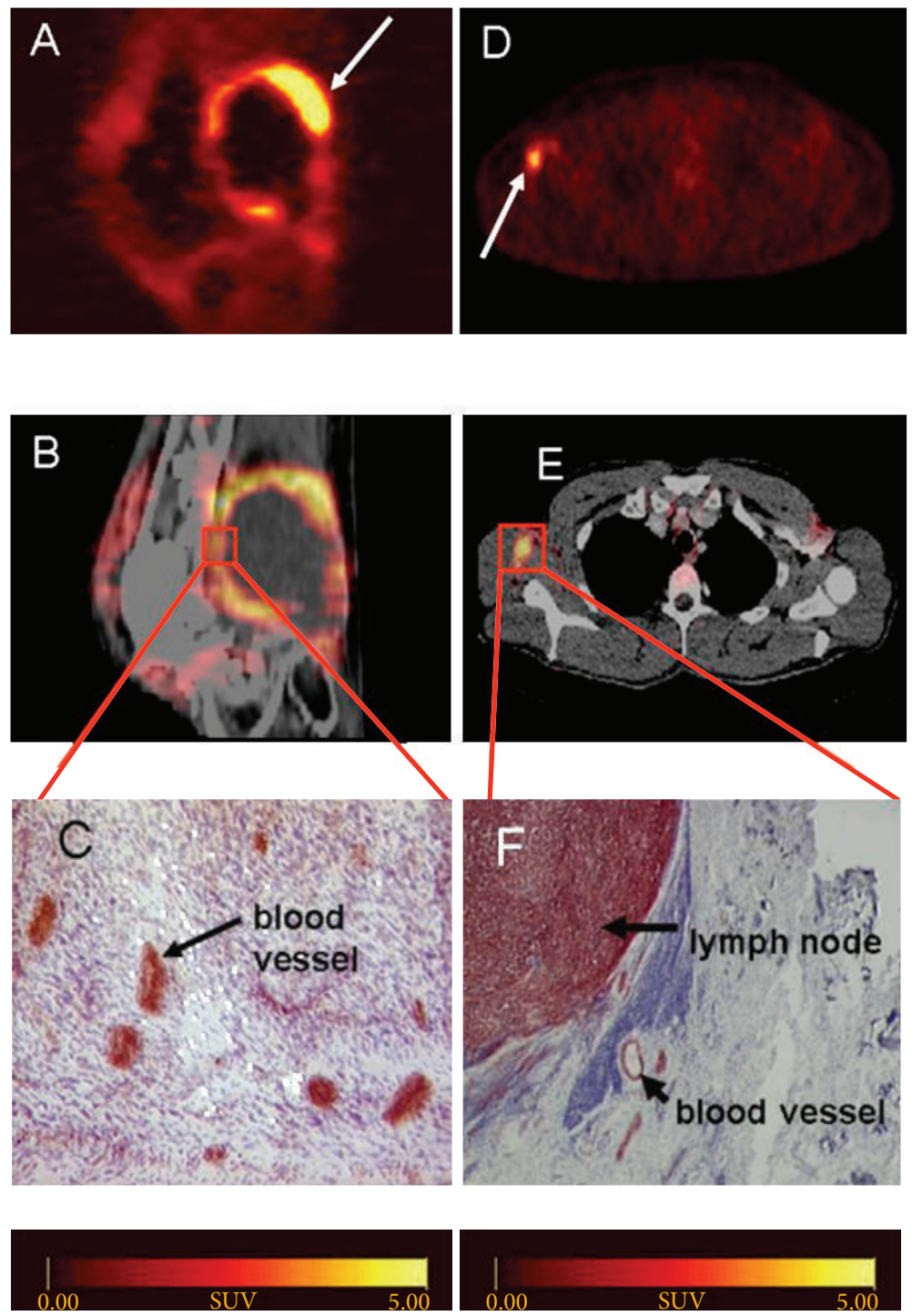

FIGURE 1: $\left[{ }^{18} \mathrm{~F}\right]$ Galacto-RGD PET: (A-C) patient with a soft tissue sarcoma dorsal of the right knee joint. (A) Sagittal section acquired 170 min p.i. (B) PET/CT image fusion. (C) Immunohistochemistry of a peripheral tumor section using the anti- $\alpha_{v} \beta_{3}$ monoclonal antibody LM609 demonstrates intense staining predominantly of tumor vasculature. (D-F) Patient with malignant melanoma and a lymph node metastasis in the right axilla. (D) Axial section acquired $140 \mathrm{~min}$ p.i. (E) PET/Ct image fusion. (F) Immunohistochemistry of the lymph node demonstrates intense staining predominantly of tumor cells and also blood vessels (with permission from Haubner et al. [17]).

normal liver tissue. Stability studies in vivo showed $74 \%$ intact tracer after $60 \mathrm{~min}$ in blood. Biodistribution and dosimetry studies in 8 healthy volunteers showed predominately renal excretion with the highest uptake in liver, combined walls of the intestine, and kidneys [58]. The compound was well tolerated with no drug-related adverse events reported. The mean effective dose was $0.026 \mathrm{mSv} / \mathrm{MBq}$ comparable to $\left[{ }^{18} \mathrm{~F}\right]$ Galacto-RGD. An advantage of $\left[{ }^{18} \mathrm{~F}\right]$ Fluciclatide compared with $\left[{ }^{18} \mathrm{~F}\right]$ Galacto-RGD is the easier availability. However, further clinical studies are needed to demonstrate the potential of this compound for imaging integrin $\alpha_{v} \beta_{3} / \alpha_{v} \beta_{5}$ expression. Anyway, preclinical studies in mice already showed that monitoring of tumor response to an antiangiogenic sunitinib therapy using $\left[{ }^{18} \mathrm{~F}\right]$ Fluciclatide-PET is feasible [59].
2.1.3. $\left.{ }^{18} \mathrm{~F}\right] R G D-K 5$. RGD-K5 is a closely related derivative to Galacto-RGD. The used cyclic pentapeptide c(RGDfK) and the sugar amino acid are identical for both compounds. The difference is found in the conjugation of 2-azidoacetic acid to the amino function of the sugar amino acid of RGD-K5 allowing labeling via "click chemistry" using 5-[ $\left[{ }^{18} \mathrm{~F}\right]$ fluoro-1pentyne. Similar to the labeling strategy using oxime formation for labeling, the click chemistry approach also reduced the overall synthesis time compared with $\left[{ }^{18} \mathrm{~F}\right]$ Galacto-RGD, thereby increasing the availability of $\left[{ }^{18} \mathrm{~F}\right] \mathrm{RGD}-\mathrm{K} 5$ [30].

Initial preclinical studies showed high affinity for integrin $\alpha_{v} \beta_{3}$ and predominantly renal elimination and high plasma stability in mice $[60,61]$. This was confirmed by biodistribution and radiation dosimetry studies in monkeys 


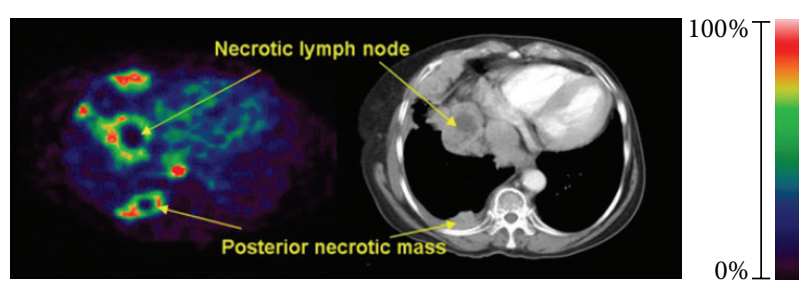

(a)

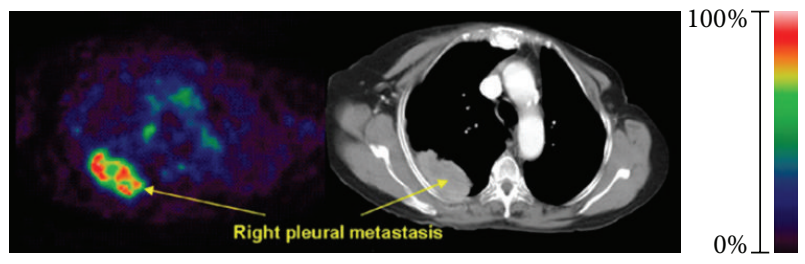

(b)

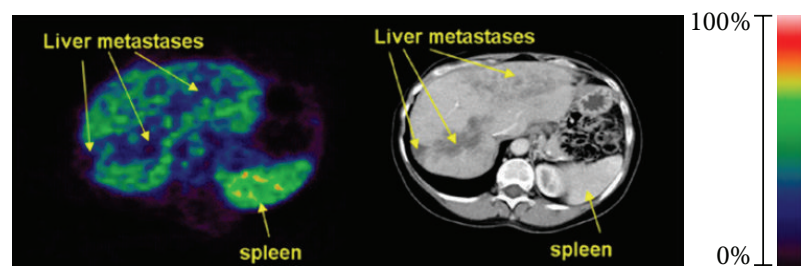

(c)

FIGURE 2: $\left[{ }^{18} \mathrm{~F}\right]$ Fluciclatide PET: (a) patient with lung and pleural metastases. (b) Intralesion heterogeneity of uptake within pleural metastasis in PET image, which was not demonstrated as necrosis on corresponding CT section. (c) Liver metastases imaged as hypointense lesions because of high background signal (high uptake in spleen is possibly due to blood pooling) (with permission from Kenny et al. [18]).

and four healthy volunteers [62]. Organs with the highest activity concentration were bladder, kidneys, gallbladder, and liver. It was found that the plasma clearance half-life was approximately $12 \mathrm{~min}$ and that approximately $44 \%$ of the injected activity had been excreted in the urine by end of the study $(\sim 2.5 \mathrm{~h})$. No clinical significant effects on vital signs had been found during the follow-up until $24 \mathrm{~h}$ after tracer injection. Depending on the bladder-voiding model the mean effective dose calculated was between 0.015 and $0.031 \mathrm{mSv} / \mathrm{MBq}$ and thus in the range of the other RGD tracers already in clinical studies. In an initial study with 12 breast cancer patients, $\left[{ }^{18} \mathrm{~F}\right] \mathrm{RGD}-\mathrm{K} 5$ PET was compared with $\left[{ }^{18}\right.$ F]FDG-PET [63]. Out of 157 lesions detected using $\left[{ }^{18} \mathrm{~F}\right]$ FDG, 122 lesions could be visualized by $\left[{ }^{18} \mathrm{~F}\right] \mathrm{RGD}-\mathrm{K} 5$. In most lesions, $\left[{ }^{18} \mathrm{~F}\right] \mathrm{FDG}$ uptake was higher as found for $\left[{ }^{18} \mathrm{~F}\right]$ RGD-K5 with no correlation between the uptake of the two compounds, confirming the results already found with other RGD tracers.

2.1.4. $\left[{ }^{68} \mathrm{Ga}\right.$ NOTA-RGD. $\left[{ }^{68} \mathrm{Ga}\right.$ NNOTA-RGD is the first ${ }^{68} \mathrm{Ga}$-labeled $\alpha_{v} \beta_{3}$ integrin-targeting compound for which initial clinical data are available. Due to the increasing availability of corresponding ${ }^{68} \mathrm{Ge} /{ }^{68} \mathrm{Ga}$ generators, this PET isotope becomes an interesting alternative to ${ }^{18} \mathrm{~F}$ especially for radiolabeling of peptides (see also below). NOTA-RGD is produced by conjugating SCN-Bz-NOTA to the amino function of the lysine in the cyclic pentapeptide $c$ (RGDyK) [34]. The chelator forms very stable complexes with ${ }^{68} \mathrm{Ga}$, allowing labeling in short reaction times even at room temperature. The compound showed high affinity for the integrin $\alpha_{v} \beta_{3}$ in in vivo binding assays and rapid predominantly renal excretion with good tumor-to-background ratios in murine tumor models [34].

A biodistribution and radiation dosimetry study with 10 patients with lung cancer or lymphoma confirmed the excretion route with the highest activity found in kidneys and urinary bladder [64]. Comparably high radioactivity was also found in the liver. The effective dose was between 0.021 and $0.025 \mathrm{mSv} / \mathrm{MBq}$ depending on the calculation model and the voiding interval. Although tumor patients were included in this study, no information concerning tumor uptake was found. Anyway, in a preliminary study with six patients with liver metastases of a colorectal carcinoma in three out of the six patients increased $\left[{ }^{68} \mathrm{Ga}\right]$ NOTA-RGD uptake in the liver lesions could be detected [65]. Moreover, the patients who showed $\left[{ }^{68} \mathrm{Ga}\right]$ NOTA-RGD uptake revealed partial response after an antiangiogenic therapy with FOLFOX and bevacizumab, whereas the other half showed stable or progressive disease.

2.1.5. $\left[{ }^{18} \mathrm{~F}\right]$ Alfatide. Attempts optimizing the strategies in labeling peptides with ${ }^{18} \mathrm{~F}$ led to the introduction of ${ }^{18} \mathrm{~F}$ aluminum fluoride [66]. This compound behaves similarly to radiometals concerning formation of complexes with, for example, NOTA derivatives introducing the advantage of using much faster and easier labeling protocols than those needed for ${ }^{18} \mathrm{~F}$-labeling using prosthetic group strategies. The first compound of this class of tracer studied in patients is the ${ }^{18} \mathrm{~F}$-labeled dimeric RGD-peptide $\left[{ }^{18} \mathrm{~F}\right]$ AlF-NOTAPRGD2 ( $\left[{ }^{18} \mathrm{~F}\right]$ Alfatide) [67]. It includes, besides the two cyclic RGD peptides $c($ RGDyK) bridged via a lysine, a PEG moiety as pharmacokinetic modifier and a Bz-NOTA moiety for complexation of " $\left[{ }^{18} \mathrm{~F}\right] \mathrm{AlF}$." In a pilot study including nine patients with lung cancer, $\left[{ }^{18} \mathrm{~F}\right]$ Alfatide allowed identification of all tumors with SUVs of $2.9 \pm 0.1$ indicating a lower variance in tumor uptake as found by most other studies using RGD-derivatives in patients [19]. Major uptake was found in kidneys and bladder indicating renal excretion. Liver, spleen, and intestine showed comparable uptake as found in the tumor (Figure 3). Kinetic modeling based on dynamic PET scans suggested specific binding of the tracer. Moreover, immunohistochemical staining confirmed $\alpha_{v} \beta_{3}$ expression on both the tumor cells and the neovasculature of the squamous carcinoma patients.

2.2. Recent Tracer Developments for Imaging Integrin $\alpha_{v} \beta_{3} / \alpha_{v} \beta_{5}$ Expression. Since the first radiotracer for imaging integrin $\alpha_{v} \beta_{3}$ has been introduced in 1999 [46], a great variety of different derivatives have been described and a selection of optimization strategies have been introduced including optimization of the pharmacokinetics (e.g., glycosylation 


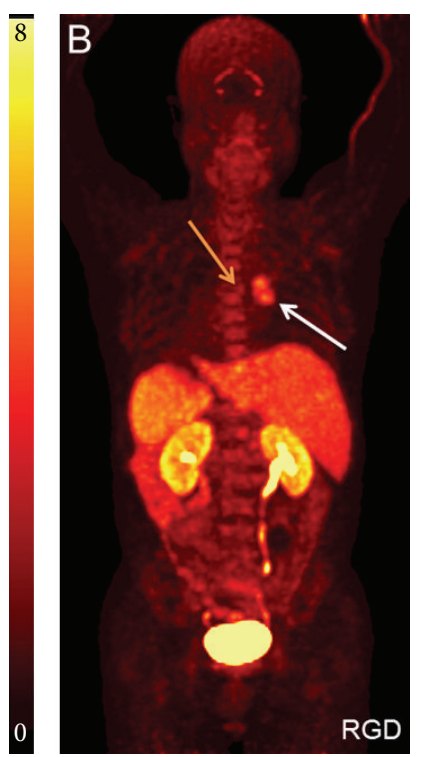

FIGURE 3: $\left[{ }^{18} \mathrm{~F}\right]$ Alfatide PET: maximum intensity projection imaging of a patient with primary squamous carcinoma (white arrow) and lymph node metastasis (yellow arrow) (with permission from Wan et al. [19]).

and PEGylation), the binding affinity (multimerization), and the labeling strategies. There are already a range of reviews dealing with the different aspects (e.g., $[6,8]$ ). Here, we focus on the most recent approaches in introducing new or optimized labeling strategies.

2.2.1. ${ }^{68}$ Ga-Labeled Derivatives. Preclinical as well as clinical data demonstrated successful noninvasive determination of integrin $\alpha_{v} \beta_{3}$ expression with $\left[{ }^{18} \mathrm{~F}\right]$ Galacto-RGD PET (see $[17,49,50,52]$ and above). The major drawback of this compound is the complex and time consuming labeling strategy using $\left[{ }^{18} \mathrm{~F}\right]$ fluoropropionic acid as prosthetic group. One strategy to overcome this problem is based on the introduction of ${ }^{68} \mathrm{Ga}$. Due to the increasing amount of commercially available ${ }^{68} \mathrm{Ga} /{ }^{68} \mathrm{Ge}$ generators [68], this isotope becomes an interesting alternative to ${ }^{18} \mathrm{~F}$, especially when peptide labeling is considered. Direct labeling of peptides modified with the corresponding chelator systems with ${ }^{68} \mathrm{Ga}$ avoids the time consuming preparation of prosthetic groups usually needed for labeling peptides with ${ }^{18} \mathrm{~F}$.

First approaches to introduce ${ }^{68} \mathrm{Ga}$-labeled RGD peptides are focused on the use of DOTA-conjugated RGD peptides. $\left[{ }^{68} \mathrm{Ga}\right.$ ]DOTA-RGD showed high affinity for the integrin $\alpha_{v} \beta_{3}$ in in vitro binding studies and receptor selective tracer accumulation in a murine tumor model [35]. However, high protein bound activity was also found compared to the ${ }^{111}$ In-labeled analog. The high plasma protein binding leads to increased activity concentration in blood and to inferior imaging properties compared with $\left[{ }^{18} \mathrm{~F}\right]$ GalactoRGD. Although DOTA is successfully used in DOTA-TOC and derivatives for binding of ${ }^{68} \mathrm{Ga}$, it is known that the cyclododecane ring of DOTA does not have the optimal size for complexing gallium [69]. A more favorable chelating system is the NOTA system, which contains a nine-membered ring more suitable for binding ${ }^{68} \mathrm{Ga}$. This system was initially introduced with NOTA-RGD [34] and NODAGA-RGD [36, 70]. The later showed significantly reduced binding to plasma proteins compared to $\left[{ }^{68} \mathrm{Ga}\right]$ DOTA-RGD resulting in equal imaging properties in a murine tumor model as found for $\left[{ }^{18} \mathrm{~F}\right]$ Galacto-RGD. Moreover, due to the high complex binding constant labeling of NODAGA-RGD can be carried out at room temperature with low amounts of peptide in high radiochemical yield and purity. Based on these positive results initial clinical studies are most recently started.

The last few years, alternative chelating systems have been introduced for ${ }^{68} \mathrm{Ga}$-labeling of RGD peptides. This include RGD peptides conjugated to $\mathrm{H}_{2}$ dedpa derivatives [38] and TRAP(RGD) 3 [20]. Based on the $\mathrm{H}_{2}$ dedpa scaffold a monomeric and a dimeric tracer have been introduced ( $\mathrm{H}_{2}-\mathrm{RGD}-1$ and $\left.\mathrm{H}_{2}-\mathrm{RGD}-2\right)$. Both compounds showed rapid ${ }^{68} \mathrm{Ga}$-labeling at room temperature in high radiochemical yield. The complexes were stable if challenged with transferrin and showed $\mathrm{IC}_{50}$ values determined using a competitive cell binding assay of approximately $2.4 \mu \mathrm{M}$ for the monomeric $\mathrm{H}_{2}$-RGD-1 and approximately $0.2 \mu \mathrm{M}$ for the dimeric $\mathrm{H}_{2}-\mathrm{RGD}-2$. Anyway, in biodistribution as well as small animal PET studies high activity concentration was found in blood even 2 hours after injection making these compounds uncompetitive with the already introduced ${ }^{68} \mathrm{Ga}$ labeled derivatives. Although no $\log P$ values are described, it is assumed that the aromatic components of the chelating systems increase the lipophilicity which might be the reason for this finding.

The TRAP chelator uses the similar nine-membered ring system as found in NOTA but possesses phosphinic acid groups instead of the carboxylic acid groups. This modification results in two advantages: (a) due to the high binding affinity of the chelator for gallium it allows labeling with very low amounts of TRAP-modified peptides and (b) due to the additional functionality of the phosphinic acid it allows direct conjugation of up to three targeting peptides per chelating system, making it an advantage system for introducing the multimerization approach. Based on these results, the trimeric TRAP(RGD) ${ }_{3}$ was introduced [20]. This compound demonstrated rapid labeling using low peptide amounts, resulting in specific activities of up to $1 \mathrm{TBq} / \mu \mathrm{mol}$, very high binding affinity for the integrin $\alpha_{v} \beta_{3}$ in a competitive cell binding assay, and good tumor/background ratios in a murine tumor model. Anyway, direct comparison of the biodistribution data in the murine M21/M21-L tumor model with $\left[{ }^{68} \mathrm{Ga}\right]$ NODAGA-RGD $90 \mathrm{~min}$ after injection showed comparable values for both compounds indicating that, despite better performance in vitro, the in vivo effect is negligible (Figure 4). Most recently, [ ${ }^{68} \mathrm{Ga}$ ]NOPO-RGD was introduced [37]. This chelator belongs to the "TRAP family" with the known advantages of fast complexation kinetics, high stability, and extremely high resulting specific activity. Major difference is found in the fact that only one phosphinic acid group is functionalized for conjugation to peptides. Thus, multimeric compounds cannot be produced. But the 


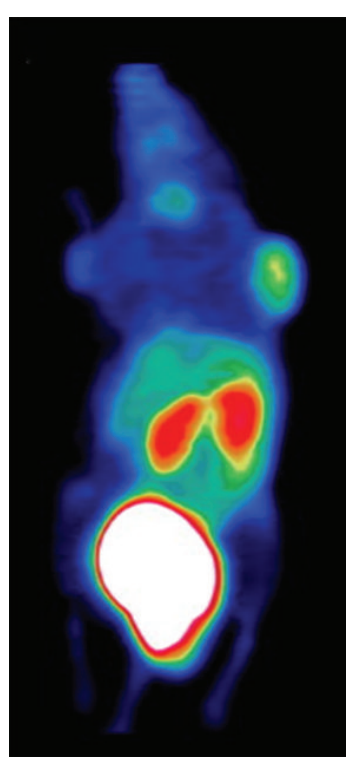

(a)

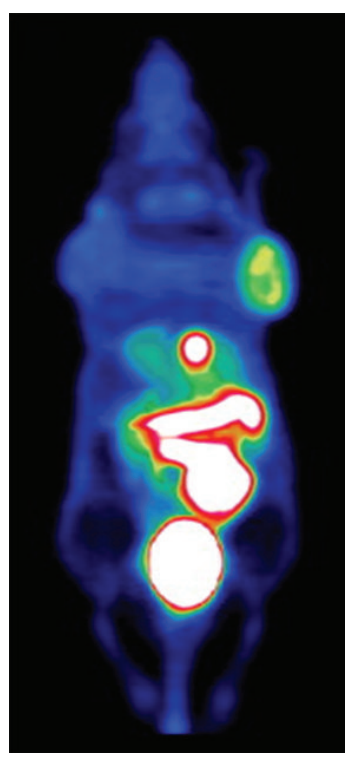

(b)

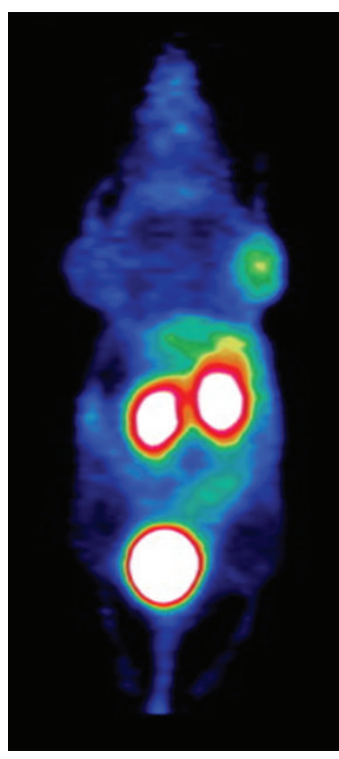

(c)

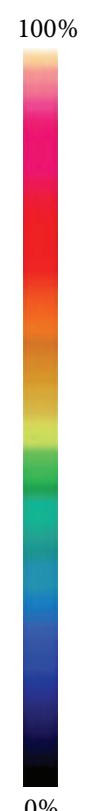

$0 \%$

FIGURE 4: $\left[{ }^{68} \mathrm{Ga}\right]$ TRAP(RGD) ${ }_{3}$ : comparison of maximum intensity projections of microPET scans of the same M21/M21L human melanoma xenografted mouse (a) $\left[{ }^{68} \mathrm{Ga}\right] \mathrm{TRAP}(\mathrm{RGD})_{3}$, (b) $\left[{ }^{18} \mathrm{~F}\right] \mathrm{Galacto}-\mathrm{RGD}$, (c) $\left[{ }^{68} \mathrm{Ga}\right]$ NODAGA-RGD (scaling adapted to show equal intensities in M21 tumors and background. Scale indicates percentage of the maximum displayed signal level) (with permission from Notni et al. [20]).

additional hydroxymethyl groups increase the polarity of any conjugated peptide and may improve renal elimination.

2.2.2. RGD Peptides Labeled with ${ }^{18} \mathrm{~F}$ via Click Chemistry Approaches. After the $\mathrm{Cu}(\mathrm{I})$-catalyzed azide-alkyne 1,3cycloaddition (CuAAC) reaction (better known as the most prominent example of "click chemistry") was introduced for radiolabeling with ${ }^{99 m} \mathrm{Tc}$ in 2006 [71], this technique was also applied for ${ }^{18} \mathrm{~F}$-labeling of RGD peptides. The apparent advantages of the $\mathrm{CuAAC}$ reaction are mainly reflected by their high yield under mild conditions, its chemoselectivity, and the formation of 1,2,3-triazole with similar polarity and size as found in an amide bond [72]. Most importantly, for peptide labeling, there are no interferences with common functionalities found in amino acid side chains. These aspects make click chemistry based approaches an interesting alternative to common prosthetic group techniques for labeling peptides with ${ }^{18} \mathrm{~F}$, as highlighted by the reviews of Kettenbach et al. [73] and Maschauer and Prante [74] within this special issue. In general, there are two possible approaches for the CuAAC reaction: either a ${ }^{18} \mathrm{~F}$-labeled organoazide or a ${ }^{18} \mathrm{~F}$ labeled alkyne is used as prosthetic group.

In a preliminary study, a dimeric RGD peptide was modified with an azide and as prosthetic group a ${ }^{18} \mathrm{~F}$ fluoro-PEG-alkyne derivative was used [31]. The product could be achieved in good radiochemical yield. Anyway, this procedure includes two HPLC separation steps, rendering it unfavorable compared to other prosthetic group labeling techniques. Glaser et al. compared the ${ }^{18} \mathrm{~F}$-labeling of RGD peptides via oxime formation, click labeling, and S-alkylation [29]. The prosthetic groups include $\left[{ }^{18} \mathrm{~F}\right]$ fluorobenzaldehyde,
2- $\left[{ }^{18} \mathrm{~F}\right]$ fluoroethylazide, and $\left[{ }^{18} \mathrm{~F}\right]$ fluoropropanethiol. It was concluded that the click labeling resulted in comparable yields as found for the fluorobenzaldehyde approach without the need for purification of the prosthetic group. However, $2-\left[{ }^{18} \mathrm{~F}\right]$ fluoroethylazide seems to be too small to be separated from the labeled RGD peptide. For the synthesis of $\left[{ }^{18} \mathrm{~F}\right] \mathrm{RGD}-\mathrm{K} 5,\left[{ }^{18} \mathrm{~F}\right]$ fluoropentyne was used as prosthetic group. With an optimized protocol for radiosynthesis the peptide could be labeled within 70 min with $35 \%$ radiochemical yield (EOB) [30]. Due to the good preclinical performance, this compound is already studied in patients (see also above).

Introduction of sugar derivatives as pharmacokinetic modifier has successfully been introduced with $\left[{ }^{18} \mathrm{~F}\right]$ GalactoRGD [47] and was later also used with $\left[{ }^{18} \mathrm{~F}\right]$ RGD-K5 [30]. Maschauer et al. combined the click labeling approach with the introduction of sugar derivatives allowing labeling as well as pharmacokinetic optimization in one step $[32,75,76]$. Four different sugar azides have been used as prosthetic groups, including glucose, galactose, maltose, and cellobiose derivatives, which were conjugated via propargylglycine to the modified RGD peptide. The overall synthesis time was in the range of 70-75 min with decay-uncorrected radiochemical yields between $16 \%$ and $24 \%$. A favorable performance was found for $\left[{ }^{18} \mathrm{~F}\right] \mathrm{Mlt}-\mathrm{RGD}$, revealing comparable tumor-tobackground ratios as found for $\left[{ }^{18} \mathrm{~F}\right]$ Galacto-RGD with the advantage of a more rapid and simplified radiosynthesis [32].

2.2.3. ${ }^{18} \mathrm{~F} /{ }^{19} \mathrm{~F}$ Isotopic Exchange and ${ }^{18}$ F-Fluoride Aluminum Complexes for Labeling RGD Peptides. Despite a great variety of studies focused on the optimization of ${ }^{18} \mathrm{~F}$-labeling of 


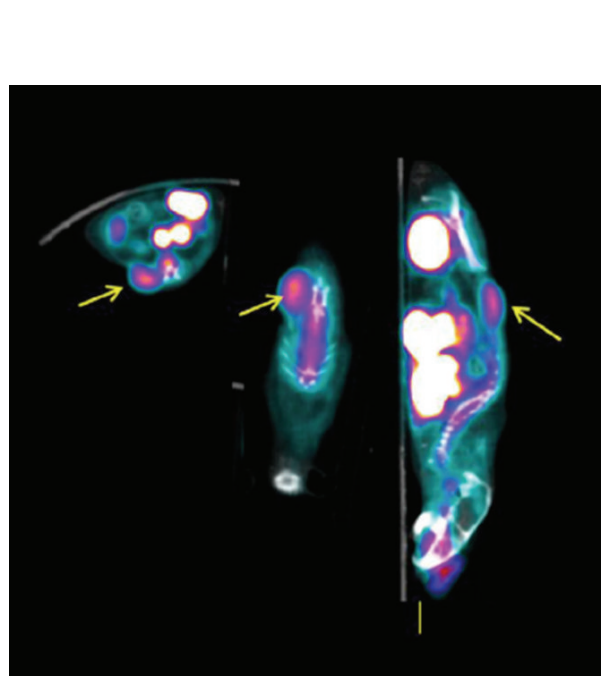

(a)

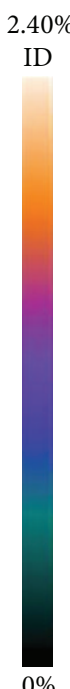

ID

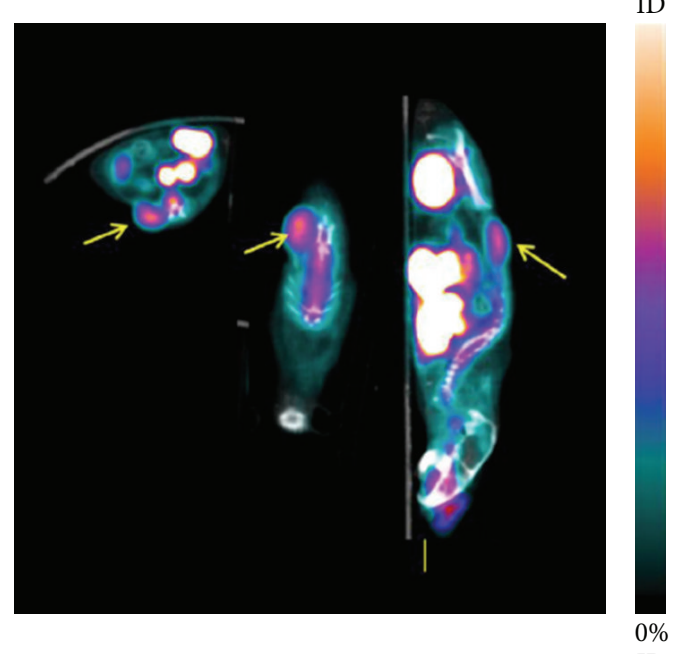

ID

$2.40 \%$

ID

(b)

Figure 5: RGD- $\left[{ }^{18} \mathrm{~F}\right] \mathrm{ArBF}_{3}^{-}$: PET/CT images of (a) an unblocked and (b) a blocked mouse. Arrow marks the tumor in three perspectives (with permission from Liu et al. [21]).

RGD peptides including some approaches with improved labeling conditions compared to $\left[{ }^{18} \mathrm{~F}\right]$ Galacto-RGD, none of the newly introduced prosthetic group approaches can compete with the simple and rapid labeling strategies based on ${ }^{68} \mathrm{Ga}$. Thus, alternative ${ }^{18} \mathrm{~F}$-labeling approaches have been studied for labeling RGD peptides including isotopic exchange strategies using silicon fluoride acceptors (SiFA) [33] or arylfluoroborates [21] as well as complexation of an ${ }^{18}$ F-aluminum fluoride species (AlF) [77].

The SiFA method is based on ${ }^{18} \mathrm{~F}$-labeling of $\mathrm{p}$-(ditert-butylfluorosilyl) benzaldehyde. It has been shown that this labeling precursor allows isotopic exchange in almost quantitative yields, resulting in unexpected high specific activities [33], which are even higher as specific activities found for peptides labeled via conventional n.c.a. ${ }^{18}$ F-labeling techniques, without HPLC purification. Conjugation of the prosthetic group was carried out via oxime formation using an aminooxy modified cyclic RGD peptide. Altogether, this results in cyclo ( $\left.\mathrm{fK}\left(\left[{ }^{18} \mathrm{~F}\right] \mathrm{SiFA}-\mathrm{AO}-\mathrm{N}\right) \mathrm{RGD}\right)$ in high radiochemical yield within approximately one hour. In vitro and in vivo evaluation of the compound still remains to be elucidated to demonstrate the imaging properties of this RGD derivative. However, a highly lipophilic precursor is needed for this labeling technique, which might negatively influence the pharmacokinetics of the radiolabeled peptides. Another strategy using radiolabeling by isotopic exchange is based on boron derivatives. It was shown that kit-like ${ }^{18}$ F-labeling resulting in an $\left[{ }^{18} \mathrm{~F}\right]$ aryl trifluoroborate-containing $\mathrm{RGD}$ peptide is feasible in high specific activity in reaction times below one hour [21]. Initial small animal PET data showed high activity concentration in bladder indicating predominantly renal elimination (Figure 5). However, despite high specific activity tracer accumulation in a murine U87MG glioblastoma model was comparably low; thus, further studies are needed to finally access the quality of this kind of tracer for imaging integrin $\alpha_{v} \beta_{3}$ expression.

Recently, a technique to produce the ${ }^{18} \mathrm{~F}$-aluminum fluoride species $\left(\mathrm{Al}^{18} \mathrm{~F}\right)^{2+}$ has been introduced [66] and has shown that this compound forms stable complexes with the NOTA ligand conjugated to peptides. After optimization [78], this technique allows labeling of peptides in a onestep synthesis without HPLC purification in analogy to radiometal labeling with, for example, ${ }^{68} \mathrm{Ga}$ or ${ }^{64} \mathrm{Cu}$. Based on these developments, $\left[{ }^{18} \mathrm{~F}\right]$ Alf-NOTA-RGD 2 has been introduced [77]. In this case, labeling including HPLC could be carried out in $40 \mathrm{~min}$. In a cell binding study, the compound showed comparable $\mathrm{IC}_{50}$ values as found for the dimeric lead structure and high tumor uptake and rapid elimination from the body in a murine tumor model. Comparison of $\left[{ }^{18} \mathrm{~F}\right]$ AlF-NOTA-PRGD 2 , which differs in an additional PEG linker from the initial compound, with a dimer labeled with ${ }^{18} \mathrm{~F}$ via fluoropropionic acid as prosthetic group and a dimer labeled with ${ }^{68} \mathrm{Ga}$ using small animal PET showed comparable pharmacokinetics and quantitative parameters for all three compounds [79]. Based on this data, the so-called $\left[{ }^{18} \mathrm{~F}\right]$ Alfatide is already studied in initial clinical trials (see also above). Subsequently, the influence on different linker was studied and the labeling protocol was optimized [80]. The replacement of the HPLC separation by C-18 cartridge purification allowed production of the compound with good radiochemical yield and high radiochemical purity within $30 \mathrm{~min}$. The compounds were stable in mouse serum up to $120 \mathrm{~min}$ and the highest binding affinity using a cell binding assay as well was found for NOTA-E $\left[\mathrm{PEG}_{4}-\mathrm{c}(\mathrm{RGDfK})\right]_{2}$. However, in vivo studies using a murine glioblastoma model could not confirm the in vitro findings. The biodistribution 


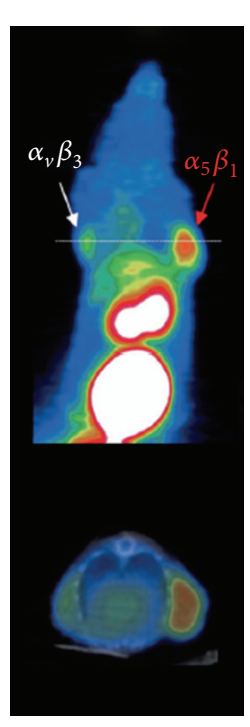

(a)

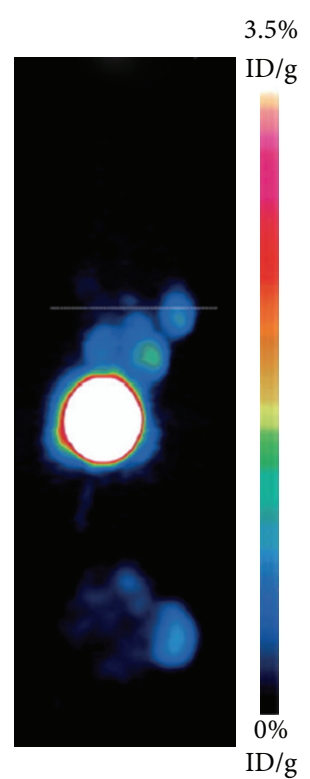

(b)

FIGURE 6: $\left[{ }^{68} \mathrm{Ga}\right] \alpha_{5} \beta_{1}$-ANT: maximum intensity projection images (MIP) of microPET scans. Upper row: mice bearing RKO ( $\alpha_{5} \beta_{1}$-positive) and M21 ( $\alpha_{v} \beta_{3}$-positive)tumor xenografts on right and left shoulder, respectively, (white arrow: M21; red arrow: RKO). Lower row: axial slices corresponding to the white line in upper row MIP images. (a) Injection of $\left[{ }^{68} \mathrm{Ga}\right] \alpha_{5} \beta_{1}$-ANT. (b) Blocking experiment (with permission from Neubauer et al. [22]).

data demonstrated comparable tumor uptake for NOTA$\mathrm{E}[\mathrm{c}(\mathrm{RGDfK})]_{2}$ and NOTA-E $\left[\mathrm{PEG}_{4}-\mathrm{c}(\mathrm{RGDfK})\right]_{2}$ but slightly better tumor-to-background ratios are found for the latter.

\section{Tracer Targeting Integrins $\alpha_{5} \beta_{1}$ and $\alpha_{v} \beta_{6}$}

As already mentioned, most work on the development of tracer for imaging integrins is dedicated to the development of compounds targeting the integrins $\alpha_{v} \beta_{3}$ and $\alpha_{v} \beta_{5}$. Recently, additional integrins came into the focus of interest. These include the integrins $\alpha_{5} \beta_{1}$ and $\alpha_{v} \beta_{6}$.

3.1. Integrin $\alpha_{5} \beta_{1}$. Heckmann et al. [81] developed based on tyrosine and azaglycine scaffolds nonpeptide antagonists of the integrin $\alpha_{5} \beta_{1}$. Comprehensive structure activity relationship studies including docking experiments with a homology model resulted in azaglycine derivatives with low nanomolar affinity for $\alpha_{5} \beta_{1}$ and up to $10^{4}$-fold higher selectivity when compared with $\alpha_{v} \beta_{3}$. The superior properties of the azaglycine derivatives compared with the tyrosine scaffold based compounds may result from enhanced rigidity of the first. Based on this data, one of the most promising azaglycine derivatives was modified by conjugation of NODAGA to the alkoxy benzoic acid moiety of the $\alpha_{5} \beta_{1}$ antagonist [22]. A competitive solid phase integrin binding assay demonstrated that this modification had no influence on binding affinity and selectivity to integrin $\alpha_{5} \beta_{1}$. A murine tumor model of mice bearing an $\alpha_{5} \beta_{1}$-positive human colon carcinoma (RKO) on the one flank and an $\alpha_{v} \beta_{3}$-positive human melanoma (M21) on the other flank confirmed receptor specific uptake and allows visualization of the $\alpha_{5} \beta_{1}$ positive tumor only (Figure 6).

A common approach to search for biological active peptides is based on phage display libraries. Screening a CX7C library including a random heptapeptide sequence flanked by two cysteine for high affinity integrin $\alpha_{5} \beta_{1}$ binder resulted in the peptide $\mathrm{H}$-Cys ${ }^{*}$-Arg-Arg-Glu-Thr-Ala-Trp-Ala-Cys ${ }^{*}$ $\mathrm{OH}\left(\mathrm{H}-\mathrm{C}^{*} \mathrm{RRETAWAC}^{*}-\mathrm{OH}\right)$ [82]. This peptide was used as lead structure for the development of a ${ }^{18} \mathrm{~F}$-labeled derivative for noninvasive imaging of integrin $\alpha_{5} \beta_{1}$ expression (more detailed information will be found in this special issue under Haubner et al. "H-CRRETAWAC-OH, a lead structure for the development of radiotracer targeting integrin $\alpha_{5} \beta_{1}$ ?" [39]). Briefly, for labeling, 2- $\left[{ }^{18} \mathrm{~F}\right]$ fluoropropionic acid was used as prosthetic group. With an isolated receptor binding assay it was demonstrated that modification of the lead structure reduced binding to integrin $\alpha_{5} \beta_{1}$ by a factor of 10. Comparison of the binding affinity for $\alpha_{5} \beta_{1}, \alpha_{v} \beta_{3}$, and $\alpha_{\mathrm{II}} \beta_{3}$ revealed that selectivity was not affected. Despite high affinity for the integrin and stability in human serum in vivo, biodistribution data of $\left[{ }^{18} \mathrm{~F}\right]$ FProp- $\mathrm{C}^{*}$ RRETAWAC ${ }^{*}-\mathrm{OH}$ using a murine tumor model were disappointing. In fact, the highest tracer accumulation was found for the tumor, but similar high radioactivity concentration was found in blood. Additionally, activity concentration in the organs remains almost constant over the observation period of 120 min leading to tumor-tobackground ratios between 1 and 2, making this compound not suitable for imaging integrin $\alpha_{5} \beta_{1}$ expression.

3.2. Integrin $\alpha_{v} \beta_{6}$. The most prominent lead structure for the development of radiotracer for imaging integrin 

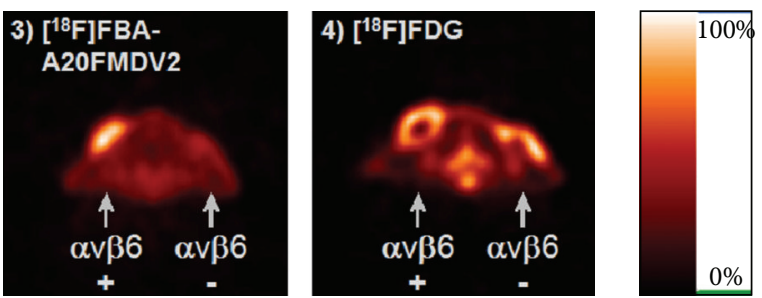

FIgURE 7: $\left[{ }^{18} \mathrm{~F}\right]$ FBA-A20FMDV2: (3) representative transaxial microPET 45-60 min after injection. The positive $\left(\alpha_{v} \beta_{6}\right.$-expressing DX3puro $\beta 6$ ) tumors were located near the left shoulder and the negative (control DX3puro) tumors near the right shoulder. For comparison, (4) depicts a $\left[{ }^{18} \mathrm{~F}\right] \mathrm{FDG}$ scan of the animal shown in (3), obtained within $5 \mathrm{~d}$. (with permission form Hausner et al. [23]).

$\alpha_{v} \beta_{6}$ is the 20 -amino acid peptide A20FMDV2 (sequence: NAVPNLRGDLQVLAQKVART). The sequence is derived from the GH loop of an envelope protein of the foot-andmouth diseases virus (FMDV) [83] which mediates FMDV infection via binding to the integrin $\alpha_{v} \beta_{6}[84,85]$. The central binding region includes the RGD sequence followed by an LXXL motif, where X specifies variable amino acids. Phage display libraries indicate that the DLXXL sequence is responsible for the high $\alpha_{v} \beta_{6}$ specificity [86].

This peptide was initially labeled with a $\left[{ }^{18} \mathrm{~F}\right]$ fluorobenzoyl group via a solid-phase labeling strategy [23]. In a competitive binding ELISA including integrin $\alpha_{v} \beta_{6}, \alpha_{v} \beta_{3}$, $\alpha_{v} \beta_{5}$, and $\alpha_{5} \beta_{1}$ it was demonstrated that the $\mathrm{N}$-terminal modification has no influence on binding affinity and selectivity. Evaluation of the tracer using a murine tumor model including $\alpha_{v} \beta_{6}$-positive (DX3puro) and $\alpha_{v} \beta_{6}$-negative (DX3puro $\beta 6$ ) xenografts demonstrated receptor selective uptake of $\left[{ }^{18} \mathrm{~F}\right]$ FBA-A20FMDV2 (Figure 7) [23]. However, uptake and retention in the tumor were comparably low, which might be due to the low metabolic stability of the compound. To improve the stability and the pharmacokinetic behavior, polyethylene glycol (PEG) moieties have been introduced. This resulted in $\left[{ }^{18} \mathrm{~F}\right] \mathrm{FBA}-\mathrm{PEG}_{28}-\mathrm{A} 20 \mathrm{FMDV} 2$ and $\left[{ }^{18} \mathrm{~F}\right] \mathrm{FBA}-\left(\mathrm{PEG}_{28}\right)_{2}$-A20FMDV2 [40]. HPLC analysis of mouse urine samples showed increased stability of the PEGylated compounds with only one major metabolite detected. Also tumor retention could be significantly improved with almost constant uptake up to $4 \mathrm{~h}$ after injection. However, also retention in other organs has been increased. In particular, the introduction of a second $\mathrm{PEG}_{28}$ unit was not beneficial due to the resulting high uptake and retention in the kidneys. Most recently, Hausner et al. [41] evaluated the copper-free, strain-promoted click chemistry for ${ }^{18} \mathrm{~F}$-labeling of A20FMDV2. This modified click chemistry approach should eliminate the need for potentially toxic copper catalysts. The radiotracer was readily prepared with high radiochemical purity, but the required cyclooctyne derivative introduces a very lipophilic moiety which negatively influences the pharmacokinetic of the resulting $\left[{ }^{18} \mathrm{~F}\right] \mathrm{FBA}-\mathrm{C}_{6}-\mathrm{ADIBON}_{3}-\mathrm{PEG}_{7}-\mathrm{A} 20 \mathrm{FMDV} 2$. Thus, despite receptor specific binding and good metabolic stability, the tumor uptake was low and the radioactivity concentration in urine as well as gall bladder was very high, indicating both renal and hepatobiliary elimination making this compound not suitable for imaging integrin $\alpha_{v} \beta_{6}$ expression.

Additional approaches are based on the introduction of chelating systems for labeling with ${ }^{111}$ In-indium or ${ }^{64} \mathrm{Cu}-$ copper. For ${ }^{111}$ In-labeling, DTPA was conjugated to the Nterminal end of the peptide [42]. DTPA conjugation has no effect on peptide binding affinity and receptor specificity. Serum stability was comparable as found for $\left[{ }^{18} \mathrm{~F}\right] \mathrm{FBA}$ A20FMDV2 with several metabolites found after $4 \mathrm{~h}$ incubation. Despite comparable low stability, tumor uptake was higher as found for the ${ }^{18} \mathrm{~F}$-labeled derivative. If this could be ascribed to the different tumor models used or to a better performance of the [ $\left.{ }^{111} \mathrm{In}\right]$ DTPA-A20FMDV2, it has to be figured out by direct comparison in the same animal model. Extremely high radioactivity concentration was found in kidneys at 1 hour after injection. Other organs with comparable uptake as found in the tumor are lower gastrointestinal tract, gall bladder, and stomach. This seems to be due to expression of the integrin $\alpha_{v} \beta_{6}$ in these organs, which were examined by immunohistochemical staining of the corresponding paraffin-embedded murine tissue and confirmed by blocking studies. High-resolution SPECT of mice demonstrate clear visualization of $\alpha_{v} \beta_{6}$-expressing tumors but also indicate high activity concentration in kidneys and bladder. [ ${ }^{111}$ In]DTPAA20FMDV2 was also used to study imaging of $\alpha_{v} \beta_{6}$ integrin for molecular stratification of idiopathic pulmonary fibrosis [87]. It could be demonstrated that levels of [ ${ }^{111}$ In]DTPAA20FMDV2 in the lung correlated positively with hydroxyproline, $\alpha_{v} \beta_{6}$ protein, and itgb6 messenger RNA levels indicating that this technique might be feasible to be used for stratifying therapy for patients with pulmonary fibrosis.

A study by $\mathrm{Hu}$ et al. [43] was designed to determine the best candidate out of four chelating systems to label $\mathrm{PEG}_{28}$ A20FMDV2 with ${ }^{64} \mathrm{Cu}$. This include a triazacyclononane derivative (NOTA), a tetraazacyclododecane derivative (DOTA), a tetraazabicyclo[6.6.2] hexadecane derivative (CB-TE1A1P), and a hexaazabicyclo[6.6.6]icosane derivative (BaBaSar). Independent of the chelating system, all compounds could be labeled under mild conditions in good radiochemical purity and specific activity. None of the chelating systems influenced the selectivity for the integrin $\alpha_{v} \beta_{6}$ in a cell binding assay. The lowest binding and internalization were found for $\left[{ }^{64} \mathrm{Cu}\right] \mathrm{NOTA}-\mathrm{PEG}_{28}-\mathrm{A} 20 \mathrm{FMDV} 2$. Stability studies in mouse serum after 24 hours incubation revealed the highest amount of intact tracer for $\left[{ }^{64} \mathrm{Cu}\right] \mathrm{CB}-\mathrm{TE} 1 \mathrm{~A} 1 \mathrm{P}-\mathrm{PEG}_{28}$ A20FMDV2 $(<45 \%)$ and the lowest for $\left[{ }^{64} \mathrm{Cu}\right] \mathrm{BaBaSar}-$ $\mathrm{PEG}_{28}-\mathrm{A} 20 \mathrm{FMDV} 2$ (14\%). Initial biodistribution data did not present the best candidate. Although high positive-tonegative tumor uptake ratios were found for $\left[{ }^{64} \mathrm{Cu}\right] \mathrm{CB}$ TE1A1P-PEG 28 -A20FMDV2 and for [ $\left.{ }^{64} \mathrm{Cu}\right] \mathrm{BaBaSar}-\mathrm{PEG}_{28}$ A20FMDV2, there was significant higher kidney uptake as found for the other two tracers. Another unpredicted finding was that blocking resulted only for three compounds in a reduced uptake in the receptor-positive tumor. For $\left[{ }^{64} \mathrm{Cu}\right]$ NOTA-PEG 28 -A20FMDV2, an unexplained increase of tumor uptake was found. Altogether, this study demonstrated that ${ }^{64} \mathrm{Cu}$-labeling of A20FMDV2 derivatives is 


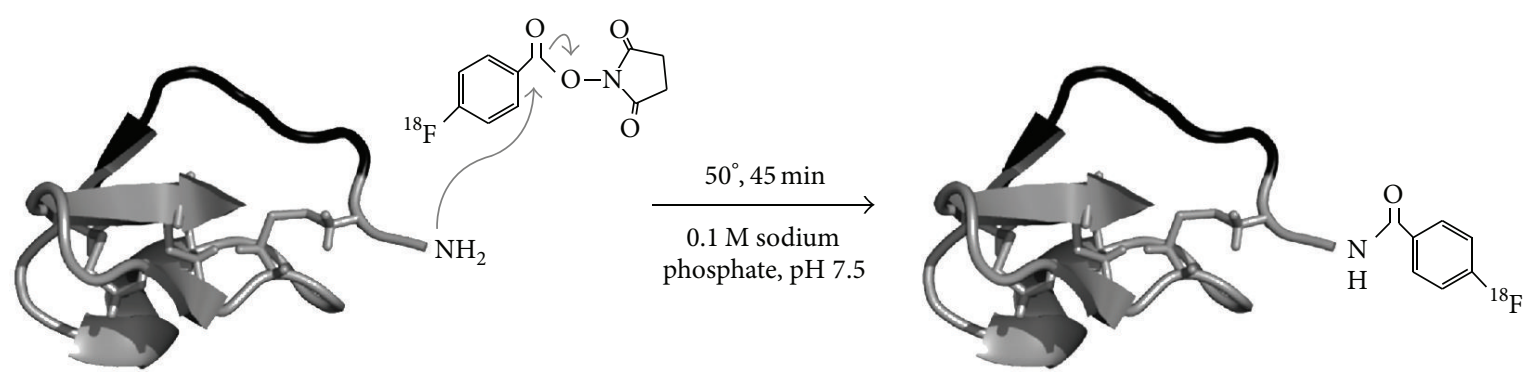

$\mathrm{R}_{0} 1$ GCILNMRTDLGTLLFRCRRDSDCPGACICRGNGYCG
$\mathrm{S}_{0} 2$ GCRSLARTDLDHLRGRCSSDSDCLAECICLENGFCG

(a)

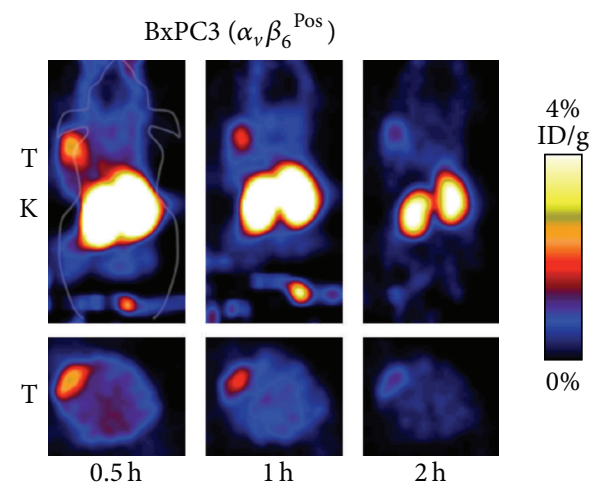

(b)

Figure 8: Cystine knot based tracer: (a) $\mathrm{R}_{0} 1$ and $\mathrm{S}_{0} 2$ are cystine knot peptides that contain 3 disulfide bonds, an active binding loop (black), and a sole primary amine at $\mathrm{N}$ terminus used for labeling via ${ }^{18} \mathrm{~F}-\mathrm{SFB}$. Peptide sequences are presented with conserved residues highlighted. (b) ${ }^{18} \mathrm{~F}$-fluorobenzoate- $\mathrm{R}_{0} 1$ small-animal PET imaging of BxPC3 pancreatic adenocarcinoma (integrin $\alpha_{v} \beta_{6}$-positive) bearing nude mice (fiveminute static scans were acquired at $0.5,1$, and $2 \mathrm{~h}$ p.i.; decay-corrected coronal and transverse slices are presented; tumor (T) and kidneys (K) are marked on images) (with permission from Hackel et al. [24]).

possible but much more detailed experiments that may be also including alternative chelating systems are necessary before a final decision about the best performer can be made.

To develop a more stable and effective agent for imaging integrin $\alpha_{v} \beta_{6}$ cysteine knot peptides were engineered which demonstrated nanomolar affinity for this integrin [44]. Four DOTA-derivatized compounds were labeled with ${ }^{64} \mathrm{Cu}$ and metabolic stability was studied in mouse serum. Two derivatives ([$\left.{ }^{64} \mathrm{Cu}\right]$ DOTA- $\mathrm{S}_{0} 2$ and $\left[{ }^{64} \mathrm{Cu}\right]$ DOTA-E $\left.\mathrm{E}_{0} 2\right)$ showed high stability with more than $95 \%$ intact tracer after 24 hours incubation. In vivo biodistribution as well as small animal PET demonstrated receptor specific tumor uptake for all compounds tested but also extremely high activity concentration in kidneys for $\left[{ }^{64} \mathrm{Cu}\right] \mathrm{DOTA} \mathrm{R}_{0} 2$, $\left[{ }^{64} \mathrm{Cu}\right]$ DOTA- $\mathrm{E}_{0} 2$, and $\left[{ }^{64} \mathrm{Cu}\right]$ DOTA- $\mathrm{R}_{0} 1$. In a further study $\mathrm{R}_{0} 1$ and $\mathrm{S}_{0} 2$, were labeled via $\mathrm{N}$-succinimidyl-4${ }^{18}$ F-fluorobenzoate (Figure 8) [24]. In particular, ${ }^{18} \mathrm{~F}$ fluorobenzoate- $\mathrm{S}_{0} 2$ showed high serum stability. Despite lower stability in the in vitro assay, tumor uptake was superior for ${ }^{18} \mathrm{~F}$-fluorobenzoate- $\mathrm{R}_{0} 1$. For both compounds, a clear reduction in kidney uptake was found when compared with the ${ }^{64} \mathrm{Cu}$-labeled analogs. Anyway, with $16 \% \mathrm{ID} / \mathrm{g}$ at $1 \mathrm{~h}$ p.i. it remains high especially for ${ }^{18} \mathrm{~F}$-fluorobenzoate- $\mathrm{R}_{0} 1$. However, the results from coinjection studies remained inexplicable.
For ${ }^{18} \mathrm{~F}$-fluorobenzoate- $\mathrm{R}_{0} 1$, at least a slight reduction in tumor uptake was found, but no reduction was observed for ${ }^{18}$ F-fluorobenzoate- $S_{0} 2$. Most recently, $S_{0} 2$ was modified with a single amino acid chelator (SAAC) and labeled with ${ }^{99 m} \mathrm{Tc}$ $(\mathrm{CO})_{3}$ [45]. Similar to the other cysteine knot derivatives, $\left[{ }^{99 m} \mathrm{Tc}\right] S A A C-\mathrm{S}_{0} 2$ showed high metabolic stability and integrin $\alpha_{v} \beta_{6}$ specific uptake but biodistribution studies revealed, with exception of tumor-to-muscle ratio, that most of the tumor-to-organ ratios are approximately one or even clearly below one. Very high activity concentration is again found for the kidneys, independent of the use of the serinerich derivative, which should avoid high kidney uptake.

\section{Summary and Conclusion}

Approximately 15 years ago, the first radiolabeled RGD peptides were introduced to image integrin $\alpha_{v} \beta_{3}$. Starting from the initially iodinated derivatives, a great variety of different compounds labeled with almost the whole set of available isotopes used in nuclear medicine tracer techniques have been described, but only a small set yet entered clinical trials. The first and most intensively studied one is $\left[{ }^{18} \mathrm{~F}\right]$ GalactoRGD which showed receptor selective tracer accumulation in 
the tumor with rapid predominantly renal elimination resulting in good tumor-to-background ratios and low radiation burden for the patient. The drawback of this compound is the complex time-consuming radiosynthesis. Thus, one major goal of the subsequently developed compounds was to optimize the radiolabeling strategy. One approach was focused on alternative ${ }^{18} \mathrm{~F}$-labeling strategies including oxime formation, click chemistry, isotopic exchange labeling, and introduction of aluminum fluoride species. Another approach to develop new PET tracer was focused on the introduction of ${ }^{68} \mathrm{Ga}$ as an alternative to ${ }^{18} \mathrm{~F}$ for PET imaging. Based on each of the described labeling strategies, at least one candidate RGD peptide has entered clinical studies, with the exception of the isotopic exchange labeling strategy. All approaches produce the radiopharmaceutical in shorter production times as described for $\left[{ }^{18} \mathrm{~F}\right]$ Galacto-RGD, with most significant reductions found for the ${ }^{68} \mathrm{Ga}$-labeling approach followed by the aluminum fluoride approach. All tracers have in common that they allow receptor specific imaging of integrin $\alpha_{v} \beta_{3}$ (and $\alpha_{v} \beta_{5}$ ) expression, show rapid predominately renal excretion with low radiation burden, and are well tolerated. For most radiopharmaceuticals, a great variance in tracer uptake in the lesions is found. One exception is the dimeric tracer $\left[{ }^{18} \mathrm{~F}\right]$ Alfatide. The initial study with nine patients resulted in very low variance in the SUV. However, a clinical study directly comparing different RGD tracers is lacking; thus, a final conclusion which compound performs best is not possible, yet. However, as there are already a variety of clinical studies using radiolabeled RGD peptides demonstrating their feasibility for imaging $\alpha_{v} \beta_{3}$, it is now of utmost importance to study how patients can benefit from this PET imaging approach. Therefore, further studies have to demonstrate whether corresponding antiangiogenic therapies can be controlled using this imaging technique. Most recently, alternative applications are also studied including assessment of plaque inflammation. However, again more comprehensive studies are needed allowing a final conclusion. In parallel to the radiopharmaceuticals already in clinical studies, a set of new compounds and strategies are evaluated. Among this set of candidates, several may enter clinical trials soon, including $\left[{ }^{68} \mathrm{Ga}\right]$ NODAGA-RGD and $\left[{ }^{68} \mathrm{Ga}\right]$ TRAP(RGD $)_{3}$.

In addition to the integrins $\alpha_{v} \beta_{3} / \alpha_{v} \beta_{5}$ the integrins $\alpha_{5} \beta_{1}$ and $\alpha_{v} \beta_{6}$ recently came into the focus of interest. Integrin $\alpha_{5} \beta_{1}$ might even be more important in the angiogenic process as the integrin $\alpha_{v} \beta_{3}$; thus, initial tracer either based on nonpeptidic scaffolds or on results from screening phage display libraries has been developed. The performance of the latter was not sufficient to be used for imaging integrin $\alpha_{5} \beta_{1}$ whereas the nonpeptide derivatives seem to be promising and are the basis for further studies. Integrin $\alpha_{v} \beta_{6}$ does not seem to be involved in angiogenesis but was found to be highly expressed on a variety of tumors. Moreover, expression seems to correlate with pure outcome; thus, this integrin was also used as target structure for the development of radiopharmaceuticals. In the present days, two lead structures are studied. One is based on the sequence of a loop of an envelope protein of the foot-and-mouth diseases virus and the other is based on cystine knots. Both classes of compounds were radiolabeled with different isotopes, including ${ }^{18} \mathrm{~F}$ and ${ }^{64} \mathrm{Cu}$, and revealed receptor-specific binding in vitro and in vivo. However, on the one hand, some of the tracers lack metabolic stability and, on the other hand, tracer excretion is not optimal, leading to high activity in a variety of organs including the kidneys as the dose-limiting organ. Thus, although initial data demonstrate that $\alpha_{v} \beta_{6}$-specific imaging is feasible, further optimizations are needed to find suitable compounds for noninvasive imaging of this receptor in patients.

\section{Conflict of Interests}

The authors declare that there is no conflict of interests regarding the publication of this paper.

\section{References}

[1] C. Margadant, H. N. Monsuur, J. C. Norman, and A. Sonnenberg, "Mechanisms of integrin activation and trafficking," Current Opinion in Cell Biology, vol. 23, no. 5, pp. 607-614, 2011.

[2] J. Welti, S. Loges, S. Dimmeler, and P. Carmeliet, "Recent molecular discoveries in angiogenesis and antiangiogenic therapies in cancer," The Journal of Clinical Investigation, vol. 123, no. 8, pp. 3190-3200, 2013.

[3] M. Petrillo, G. Scambia, and G. Ferrandina, "Novel targets for VEGF-independent anti-angiogenic drugs," Expert Opinion on Investigational Drugs, vol. 21, no. 4, pp. 451-472, 2012.

[4] K. Seystahl and M. Weller, "Is there a world beyond bevacizumab in targeting angiogenesis in glioblastoma?" Expert Opinion on Investigational Drugs, vol. 21, no. 5, pp. 605-617, 2012.

[5] B. Garmy-Susini and J. A. Varner, "Roles of integrins in tumor angiogenesis and lymphangiogenesis," Lymphatic Research and Biology, vol. 6, no. 3-4, pp. 155-163, 2008.

[6] R. Haubner, A. J. Beer, H. Wang, and X. Chen, "Positron emission tomography tracers for imaging angiogenesis," European Journal of Nuclear Medicine and Molecular Imaging, vol. 37, supplement 1, pp. S86-S103, 2010.

[7] P. C. Brooks, R. A. Clark, and D. A. Cheresh, "Requirement of vascular integrin alpha v beta 3 for angiogenesis," Science, vol. 264, no. 5158, pp. 569-571, 1994.

[8] F. C. Gaertner, H. Kessler, H. J. Wester, M. Schwaiger, and A. J. Beer, "Radiolabelled RGD peptides for imaging and therapy," European Journal of Nuclear Medicine and Molecular Imaging, vol. 39, supplement 1, pp. 126-138, 2012.

[9] G. H. Mahabeleshwar, W. Feng, D. R. Phillips, and T. V. Byzova, "Integrin signaling is critical for pathological angiogenesis," The Journal of Experimental Medicine, vol. 203, no. 11, pp. 2495-2507, 2006.

[10] K. L. Goh, J. T. Yang, and R. O. Hynes, "Mesodermal defects and cranial neural crest apoptosis in $\alpha 5$ integrin-null embryos," Development, vol. 124, no. 21, pp. 4309-4319, 1997.

[11] S. Kim, K. Bell, S. A. Mousa, and J. A. Varner, "Regulation of angiogenesis in vivo by ligation of integrin $\alpha_{5} \beta_{1}$ with the central cell-binding domain of fibronectin," The American Journal of Pathology, vol. 156, no. 4, pp. 1345-1362, 2000.

[12] N. J. Boudreau and J. A. Varner, "The homeobox transcription factor hox D3 promotes integrin $\alpha_{5} \beta_{1}$ expression and function during angiogenesis," The Journal of Biological Chemistry, vol. 279, no. 6, pp. 4862-4868, 2004. 
[13] A. Bandyopadhyay and S. Raghavan, "Defining the role of integrin $\alpha_{\mathrm{v}} \beta_{6}$ in cancer," Current Drug Targets, vol. 10, no. 7, pp. 645-652, 2009.

[14] J. M. Breuss, J. Gallo, H. M. DeLisser et al., "Expression of the $\beta_{6}$ integrin subunit in development, neoplasia and tissue repair suggests a role in epithelial remodeling," Journal of Cell Science, vol. 108, no. 6, pp. 2241-2251, 1995.

[15] R. A. Clark, G. S. Ashcroft, M.-J. Spencer, H. Larjava, and M. W. Ferguson, "Re-epithelialization of normal human excisional wounds is associated with a switch from $\alpha_{\mathrm{v}} \beta_{5}$ to $\alpha_{\mathrm{v}} \beta_{6}$ integrins," British Journal of Dermatology, vol. 135, no. 1, pp. 46-51, 1996.

[16] R. C. Bates, "Colorectal cancer progression: integrin $\alpha_{\mathrm{v}} \beta_{6}$ and the epithelial-mesenchymal transition (EMT)," Cell Cycle, vol. 4, no. 10, pp. 1350-1352, 2005.

[17] R. Haubner, W. A. Weber, A. J. Beer et al., "Noninvasive visualization of the activated $\alpha_{\mathrm{v}} \beta_{3}$ integrin in cancer patients by positron emission tomography and $\left[{ }^{18} \mathrm{~F}\right]$ Galacto-RGD," PLoS Medicine, vol. 2, no. 3, article e70, 2005.

[18] L. M. Kenny, R. C. Coombes, I. Oulie et al., "Phase I trial of the positron-emitting Arg-Gly-Asp (RGD) peptide radioligand ${ }^{18}$ F-AH111585 in breast cancer patients," The Journal of Nuclear Medicine, vol. 49, no. 6, pp. 879-886, 2008.

[19] W. Wan, N. Guo, D. Pan et al., "First experience of ${ }^{18}$ F-alfatide in lung cancer patients using a new lyophilized kit for rapid radiofluorination," The Journal of Nuclear Medicine, vol. 54, no. 5, pp. 691-698, 2013.

[20] J. Notni, K. Pohle, and H.-J. Wester, "Be spoilt for choice with radiolabelled RGD peptides: preclinical evaluation of ${ }^{68} \mathrm{Ga}$ TRAP(RGD) 3 ," Nuclear Medicine and Biology, vol. 40, no. 1, pp. 33-41, 2013.

[21] Z. Liu, Y. Li, J. Lozada et al., "Kit-like ${ }^{18}$ F-labeling of RGD${ }^{19} \mathrm{~F}$-Arytrifluroborate in high yield and at extraordinarily high specific activity with preliminary in vivo tumor imaging," Nuclear Medicine and Biology, vol. 40, no. 6, pp. 841-849, 2013.

[22] S. Neubauer, F. Rechenmacher, A. J. Beer et al., "Selective imaging of the angiogenic relevant integrins $\alpha_{5} \beta_{1}$ and $\alpha_{\mathrm{v}} \beta_{3}$," Angewandte Chemie, vol. 52, no. 44, pp. 11656-11659, 2013.

[23] S. H. Hausner, D. DiCara, J. Marik, J. F. Marshall, and J. L. Sutcliffe, "Use of a peptide derived from foot-and-mouth disease virus for the noninvasive imaging of human cancer: generation and evaluation of $4-\left[{ }^{18} \mathrm{~F}\right]$ fluorobenzoyl A20FMDV2 for in vivo imaging of integrin $\alpha_{\mathrm{v}} \beta_{6}$ expression with positron emission tomography," Cancer Research, vol. 67, no. 16, pp. 7833-7840, 2007.

[24] B. J. Hackel, R. H. Kimura, Z. Miao et al., " ${ }^{18}$ F-fluorobenzoatelabeled cystine knot peptides for PET imaging of integrin $\alpha_{\mathrm{v}} \beta_{6}$," The Journal of Nuclear Medicine, vol. 54, no. 7, pp. 1101-1105, 2013.

[25] L. Auzzas, F. Zanardi, L. Battistini et al., "Targeting $\alpha_{\mathrm{v}} \beta_{3}$ integrin: design and applications of mono- and multifunctional RGD-based peptides and semipeptides," Current Medicinal Chemistry, vol. 17, no. 13, pp. 1255-1299, 2010.

[26] H. Cai and P. S. Conti, "RGD-based PET tracers for imaging receptor integrin $\alpha_{\mathrm{v}} \beta_{3}$ expression," Journal of Labelled Compounds and Radiopharmaceuticals, vol. 56, no. 5, pp. 264-279, 2013.

[27] M. Schottelius, B. Laufer, H. Kessler, and H.-J. Wester, "Ligands for mapping $\alpha_{\mathrm{v}} \beta_{3}$-integrin expression in vivo," Accounts of Chemical Research, vol. 42, no. 7, pp. 969-980, 2009.

[28] R. Haubner, B. Kuhnast, C. Mang et al., " $\left[{ }^{18}\right.$ F]Galacto-RGD: synthesis, radiolabeling, metabolic stability, and radiation dose estimates," Bioconjugate Chemistry, vol. 15, no. 1, pp. 61-69, 2004.
[29] M. Glaser, M. Solbakken, D. R. Turton et al., "Methods for ${ }^{18} \mathrm{~F}$-labeling of RGD peptides: comparison of aminooxy $\left[{ }^{18} \mathrm{~F}\right]$ fluorobenzaldehyde condensation with "click labeling" using 2- $\left[{ }^{18} \mathrm{~F}\right]$ fluoroethylazide, and $S$-alkylation with $\left[{ }^{18} \mathrm{~F}\right]$ fluoropropanethiol," Amino Acids, vol. 37, no. 4, pp. 717-724, 2009.

[30] L. Mirfeizi, J. Walsh, H. Kolb et al., "Synthesis of $\left[{ }^{18} \mathrm{~F}\right]$ RGD-K5 by catalyzed $[3+2]$ cycloaddition for imaging integrin $\alpha_{\mathrm{v}} \beta_{3}$ expression in vivo," Nuclear Medicine and Biology, vol. 40, no. 5, pp. 710-716, 2013.

[31] Z.-B. Li, Z. Wu, K. Chen, F. T. Chin, and X. Chen, "Click chemistry for ${ }^{18} \mathrm{~F}$-labeling of RGD peptides and microPET imaging of tumor integrin $\alpha_{\mathrm{v}} \beta_{3}$ expression," Bioconjugate Chemistry, vol. 18, no. 6, pp. 1987-1994, 2007.

[32] S. Maschauer, R. Haubner, T. Kuwert, and O. Prante, ${ }^{“ 18} \mathrm{~F}-$ Glyco-RGD peptides for PET imaging of integrin expression: efficient radiosynthesis by click chemistry and modulation of biodistribution by glycosylation," Molecular Pharmaceutics, vol. 11, no. 2, pp. 505-515, 2014.

[33] E. Schirrmacher, B. Wängler, M. Cypryk et al., "Synthesis of $p$ (Di-tert-butyl $\left[{ }^{18} \mathrm{~F}\right]$ fluorosilyl)benzaldehyde $\left(\left[{ }^{18} \mathrm{~F}\right] \mathrm{SiFA}-\mathrm{A}\right)$ with high specific activity by isotopic exchange: a convenient labeling synthon for the ${ }^{18} \mathrm{~F}$-labeling of $\mathrm{N}$-amino-oxy derivatized peptides," Bioconjugate Chemistry, vol. 18, no. 6, pp. 2085-2089, 2007.

[34] J. M. Jeong, M. K. Hong, Y. S. Chang et al., "Preparation of a promising angiogenesis PET imaging agent: ${ }^{68} \mathrm{Ga}$-labeled c(RGDyK)-isothiocyanatobenzyl-1,4,7-triazacyclononane-1, 4,7-triacetic acid and feasibility studies in mice," The Journal of Nuclear Medicine, vol. 49, no. 5, pp. 830-836, 2008.

[35] C. Decristoforo, I. H. Gonzalez, J. Carlsen et al., " ${ }^{\prime 68} \mathrm{Ga}-$ and ${ }^{111}$ In-labelled DOTA-RGD peptides for imaging of $\alpha_{\mathrm{v}} \beta_{3}$ integrin expression," European Journal of Nuclear Medicine and Molecular Imaging, vol. 35, no. 8, pp. 1507-1515, 2008.

[36] P. A. Knetsch, M. Petrik, C. M. Griessinger et al., "[ $\left.{ }^{68} \mathrm{Ga}\right]$ NODAGA-RGD for imaging $\alpha_{\mathrm{v}} \beta_{3}$ integrin expression," European Journal of Nuclear Medicine and Molecular Imaging, vol. 38, no. 7, pp. 1303-1312, 2011.

[37] J. Šimeček, J. Notni, T. G. Kapp, H. Kessler, and H.-J. Wester, "Benefits of NOPO as chelator in Gallium-68 peptides, exemplified by preclinical characterization of ${ }^{68} \mathrm{Ga}-\mathrm{NOPO}-\mathrm{c}(\mathrm{RGDfK})$," Molecular Pharmaceutics, vol. 11, no. 5, pp. 1687-1695, 2014.

[38] E. Boros, C. L. Ferreira, D. T. Yapp et al., "RGD conjugates of the $\mathrm{H}_{2}$ dedpa scaffold: synthesis, labeling and imaging with ${ }^{68} \mathrm{Ga}$," Nuclear Medicine and Biology, vol. 39, no. 6, pp. 785-794, 2012.

[39] R. Haubner, S. Maschauer, J. Einsiedel et al., "H-CRRETAWAC$\mathrm{OH}$, a lead structure for the development of tracer targeting integrin $\alpha_{5} \beta_{1}$ ?" BioMed Research International. In press.

[40] S. H. Hausner, C. K. Abbey, R. J. Bold et al., "Targeted in vivo imaging of integrin $\alpha_{\mathrm{v}} \beta_{6}$ with an improved radiotracer and its relevance in a pancreatic tumor model," Cancer Research, vol. 69, no. 14, pp. 5843-5850, 2009.

[41] S. H. Hausner, R. D. Carpenter, N. Bauer, and J. L. Sutcliffe, "Evaluation of an integrin $\alpha_{\mathrm{v}} \beta_{6}$-specific peptide labeled with $\left[{ }^{18} \mathrm{~F}\right]$ fluorine by copper-free, strain-promoted click chemistry," Nuclear Medicine and Biology, vol. 40, no. 2, pp. 233-239, 2013.

[42] A. Saha, D. Ellison, G. J. Thomas et al., "High-resolution in vivo imaging of breast cancer by targeting the pro-invasive integrin $\alpha_{\mathrm{v}} \beta_{6}$, 'The Journal of Pathology, vol. 222, no. 1, pp. 52-63, 2010.

[43] L. Y. Hu, N. Bauer, L. M. Knight et al., "Characterization and evaluation of ${ }^{64} \mathrm{Cu}$-labeled A20FMDV2 conjugates for imaging the integrin $\alpha_{\mathrm{v}} \beta_{6}$," Molecular Imaging and Biology, 2014. 
[44] R. H. Kimura, R. Teed, B. J. Hackel et al., "Pharmacokinetically stabilized cystine knot peptides that bind $\alpha_{v} \beta_{6}$ integrin with single-digit nanomolar affinities for detection of pancreatic cancer," Clinical Cancer Research, vol. 18, no. 3, pp. 839-849, 2012.

[45] X. Zhu, J. Li, Y. Hong et al., "99m Tc-labeled cystine knot peptide targeting integrin $\alpha_{\mathrm{v}} \beta_{6}$ for tumor SPECT imaging," Molecular Pharmaceutics, vol. 11, no. 4, pp. 1208-1217, 2014.

[46] R. Haubner, H.-J. Wester, U. Reuning et al., "Radiolabeled $\alpha_{\mathrm{v}} \beta_{3}$ integrin antagonists: a new class of tracers for tumor targeting," The Journal of Nuclear Medicine, vol. 40, no. 6, pp. 1061-1071, 1999.

[47] R. Haubner, H.-J. Wester, W. A. Weber et al., "Noninvasive imaging of $\alpha_{\mathrm{v}} \beta_{3}$ integrin expression using ${ }^{18} \mathrm{~F}$-labeled RGDcontaining glycopeptide and positron emission tomography," Cancer Research, vol. 61, no. 5, pp. 1781-1785, 2001.

[48] A. J. Beer, R. Haubner, M. Goebel et al., "Biodistribution and pharmacokinetics of the $\alpha_{\mathrm{v}} \beta_{3}$-selective tracer ${ }^{18} \mathrm{~F}$-Galacto-RGD in cancer patients," The Journal of Nuclear Medicine, vol. 46, no. 8, pp. 1333-1341, 2005.

[49] A. J. Beer, R. Haubner, M. Sarbia et al., "Positron emission tomography using $\left[{ }^{18} \mathrm{~F}\right]$ Galacto-RGD identifies the level of integrin $\alpha_{\mathrm{v}} \beta_{3}$ expression in man," Clinical Cancer Research, vol. 12, no. 13, pp. 3942-3949, 2006.

[50] A. J. Beer, R. Haubner, I. Wolf et al., "PET-based human dosimetry of ${ }^{18} \mathrm{~F}$-Galacto-RGD, a new radiotracer for imaging $\alpha_{\mathrm{v}} \beta_{3}$ expression," The Journal of Nuclear Medicine, vol. 47, no. 5, pp. 763-769, 2006.

[51] ICRP, "Radiation dose to patients from radiopharmaceuticals. Addendum 3 to ICRP Publication 53. ICRP Publication 106. Approved by the Commission in October 2007," Annals of the ICRP, vol. 38, no. 1-2, pp. 7-33, 2008.

[52] A. J. Beer, A.-L. Grosu, J. Carlsen et al., " $\left.{ }^{18} \mathrm{~F}\right]$ Galacto-RGD positron emission tomography for imaging of $\alpha_{\mathrm{v}} \beta_{3}$ expression on the neovasculature in patients with squamous cell carcinoma of the head and neck," Clinical Cancer Research, vol. 13, no. 22, pp. 6610-6616, 2007.

[53] O. Schnell, B. Krebs, J. Carlsen et al., "Imaging of integrin $\alpha_{\mathrm{v}} \beta_{3}$ expression in patients with malignant glioma by $\left[{ }^{18} \mathrm{~F}\right]$ GalactoRGD positron emission tomography," Neuro-Oncology, vol. 11, no. 6, pp. 861-870, 2009.

[54] A. J. Beer, S. Lorenzen, S. Metz et al., "Comparison of integrin $\alpha_{\mathrm{v}} \beta_{3}$ expression and glucose metabolism in primary and metastatic lesions in cancer patients: a PET study using ${ }^{18} \mathrm{~F}$ galacto-RGD and 18F-FDG," The Journal of Nuclear Medicine, vol. 49, no. 1, pp. 22-29, 2008.

[55] M. Hoshiga, C. E. Alpers, L. L. Smith, C. M. Giachelli, and S. M. Schwartz, " $\alpha_{\mathrm{v}} \beta_{3}$ integrin expression in normal and atherosclerotic artery," Circulation Research, vol. 77, no. 6, pp. 1129-1135, 1995.

[56] A. S. Antonov, F. D. Kolodgie, D. H. Munn, and R. G. Gerrity, "Regulation of macrophage foam cell formation by $\alpha_{v} \beta_{3}$ integrin: potential role in human atherosclerosis," The American Journal of Pathology, vol. 165, no. 1, pp. 247-258, 2004.

[57] A. J. Beer, J. Pelisek, P. Heider et al., "PET/CT imaging of integrin $\alpha_{\mathrm{v}} \beta_{3}$ expression in human carotid atherosclerosis," JACC: Cardiovascular Imaging, vol. 7, no. 2, pp. 178-187, 2014.

[58] B. J. McParland, M. P. Miller, T. J. Spinks et al., "The biodistribution and radiation dosimetry of the Arg-Gly-Asp peptide ${ }^{18}$ F-AH111585 in healthy volunteers," The Journal of Nuclear Medicine, vol. 49, no. 10, pp. 1664-1667, 2008.
[59] M. R. Battle, J. L. Goggi, L. Allen, J. Barnett, and M. S. Morrison, "Monitoring tumor response to antiangiogenic sunitinib therapy with ${ }^{18} \mathrm{~F}$-fluciclatide, an ${ }^{18} \mathrm{~F}$-labeled $\alpha_{\mathrm{v}} \beta_{3}$-integrin and $\alpha_{\mathrm{v}} \beta_{5}$-integrin imaging agent," The Journal of Nuclear Medicine, vol. 52, no. 3, pp. 424-430, 2011.

[60] H. C. Kolb, K. Chen, J. C. Walsh et al., "Synthesis and imaging of an ${ }^{18}$ F-labelled RGD peptide for detecting $\alpha_{\mathrm{v}} \beta_{3}$ integrin expression," Journal of Labelled Compounds and Radiopharmaceuticals, vol. 52, supplement 1, pp. S67-S73, 2009.

[61] H. Kolb, J. Walsh, Q. Liang et al., " ${ }^{18}$ F-RGD-K5: a cyclic triazolebearing RGD peptide for imaging integrin $\alpha_{\mathrm{v}} \beta_{3}$ expression in vivo," The Journal of Nuclear Medicine, vol. 50, supplement 2, p. 329, 2009.

[62] M. Doss, H. C. Kolb, J. J. Zhang et al., "Biodistribution and radiation dosimetry of the integrin marker ${ }^{18} \mathrm{~F}-\mathrm{RGD}-\mathrm{K} 5$ determined from whole-body PET/CT in monkeys and humans," The Journal of Nuclear Medicine, vol. 53, no. 5, pp. 787-795, 2012.

[63] H. J. Cho, J. D. Lee, J. Y. Park et al., "First in human evaluation of a newly developed integrin binding PET tracer, ${ }^{18} \mathrm{~F}-\mathrm{RGD}$ $\mathrm{K} 5$ in patients with breast cancer: comparison with ${ }^{18} \mathrm{~F}-\mathrm{FDG}$ uptake pattern and microvessel density," The Journal of Nuclear Medicine, vol. 50, supplement 2, p. 1910, 2009.

[64] J. H. Kim, J. S. Lee, K. W. Kang et al., "Whole-body distribution and radiation dosimetry of ${ }^{68} \mathrm{Ga}-\mathrm{NOTA}-\mathrm{RGD}$, a positron emission tomography agent for angiogenesis imaging," Cancer Biotherapy \& Radiopharmaceuticals, vol. 27, no. 1, pp. 65-71, 2012.

[65] S. Fanti, M. Farsad, and L. Mansi, PET-CT Beyond FDG: A Quick Guide to Image Interpretation, Springer, Berlin, Germany, 2010.

[66] W. J. McBride, R. M. Sharkey, H. Karacay et al., "A novel method of ${ }^{18} \mathrm{~F}$ radiolabeling for PET," The Journal of Nuclear Medicine, vol. 50, no. 6, pp. 991-998, 2009.

[67] L. Lang, W. Li, N. Guo et al., "Comparison study of $\left[{ }^{18} \mathrm{~F}\right] \mathrm{FAl}$ NOTA-PRGD2, $\left[{ }^{18} \mathrm{~F}\right]$ FPPRGD2, and $\left[{ }^{68} \mathrm{Ga}\right] \mathrm{Ga}-\mathrm{NOTA}-\mathrm{PRGD} 2$ for PET imaging of U87MG tumors in mice," Bioconjugate Chemistry, vol. 22, no. 12, pp. 2415-2422, 2011.

[68] C. Decristoforo, "Gallium-68-a new opportunity for PET available from a long shelflife generator automation and applications," Current Radiopharmaceuticals, vol. 5, no. 3, pp. 212220, 2012.

[69] E. T. Clarke and A. E. Martell, "Stabilities of trivalent metal ion complexes of the tetraacetate derivatives of 12-, 13- and 14membered tetraazamacrocycles," Inorganica Chimica Acta, vol. 190, no. 1, pp. 37-46, 1991.

[70] R. A. Dumont, F. Deininger, R. Haubner, H. R. Maecke, W. A. Weber, and M. Fani, "Novel ${ }^{64} \mathrm{Cu}-$ and ${ }^{68} \mathrm{Ga}$-labeled RGD conjugates show improved PET imaging of $\alpha_{\mathrm{v}} \beta_{3}$ integrin expression and facile radiosynthesis," The Journal of Nuclear Medicine, vol. 52, no. 8, pp. 1276-1284, 2011.

[71] T. L. Mindt, H. Struthers, L. Brans et al., "“Click to chelate”: synthesis and installation of metal chelates into biomolecules in a single step," Journal of the American Chemical Society, vol. 128, no. 47, pp. 15096-15097, 2006.

[72] V. D. Bock, H. Hiemstra, and J. H. van Maarseveen, " $\mathrm{Cu}^{I}-$ catalyzed alkyne-azide "click" cycloadditions from a mechanistic and synthetic perspective," European Journal of Organic Chemistry, vol. 2006, no. 1, pp. 51-68, 2006.

[73] K. Kettenbach, H. Schieferstein, and T. Ross, " ${ }^{18}$ F-labeling using click cycloadditions," BioMed Research International. In press.

[74] S. Maschauer and O. Prante, "Sweetening pharmaceutical radiochemistry by ${ }^{18}$ F-fluoroglycosylation: a short review," BioMed Research International. In press. 
[75] S. Maschauer and O. Prante, "A series of 2-O-trifluoromethylsulfonyl-D-mannopyranosides as precursors for concomitant ${ }^{18}$ F-labeling and glycosylation by click chemistry," Carbohydrate Research, vol. 344, no. 6, pp. 753-761, 2009.

[76] S. Maschauer, J. Einsiedel, R. Haubner et al., "Labeling and glycosylate of peptides using click chemistry: a general approach to ${ }^{18} \mathrm{~F}$-glycopeptides as effective imaging probes for positron emission tomography," Angewandte Chemie, vol. 49, no. 5, pp. 976-979, 2010.

[77] S. Liu, H. Liu, H. Jiang, Y. Xu, H. Zhang, and Z. Cheng, "Onestep radiosynthesis of ${ }^{18} \mathrm{~F}$-AlF-NOTA-RGD2 for tumor angiogenesis PET imaging," European Journal of Nuclear Medicine and Molecular Imaging, vol. 38, no. 9, pp. 1732-1741, 2011.

[78] W. J. McBride, C. A. D’souza, R. M. Sharkey et al., "Improved ${ }^{18} \mathrm{~F}$ labeling of peptides with a fluoride-aluminum- chelate complex," Bioconjugate Chemistry, vol. 21, no. 7, pp. 1331-1340, 2010.

[79] N. Guo, L. Lang, W. Li et al., "Quantitative analysis and comparison study of $\left[{ }^{18} \mathrm{~F}\right]$ AlF-NOTA-PRGD2, $\left[{ }^{18} \mathrm{~F}\right]$ FPPRGD2 and $\left[{ }^{68} \mathrm{Ga}\right] \mathrm{Ga}-\mathrm{NOTA}-\mathrm{PRGD} 2 \mathrm{using}$ a reference tissue model," PLoS ONE, vol. 7, no. 5, Article ID e37506, 2012.

[80] N. Guo, L. Lang, H. Gao et al., "Quantitative analysis and parametric imaging of ${ }^{18} \mathrm{~F}$-labeled monomeric and dimeric RGD peptides using compartment model," Molecular Imaging and Biology, vol. 14, no. 6, pp. 743-752, 2012.

[81] D. Heckmann, A. Meyer, B. Laufer, G. Zahn, R. Stragies, and H. Kessler, "Rational design of highly active and selective ligands for the $\alpha_{5} \beta_{1}$ integrin receptor," ChemBioChem, vol. 9, no. 9, pp. 1397-1407, 2008.

[82] E. Koivunen, B. Wang, and E. Ruoslahti, "Isolation of a highly specific ligand for the $\alpha_{5} \beta_{1}$ integrin from a phage display library," The Journal of Cell Biology, vol. 124, no. 3, pp. 373-380, 1994.

[83] D. Logan, R. Abu-Ghazaleh, W. Blakemore et al., "Structure of a major immunogenic site on foot-and-mouth disease virus," Nature, vol. 362, no. 6420, pp. 566-568, 1993.

[84] T. Jackson, D. Sheppard, M. Denyer, W. Blakemore, and A. M. Q. King, "The epithelial integrin $\alpha_{\mathrm{v}} \beta_{6}$ is a receptor for footand-mouth disease virus," Journal of Virology, vol. 74, no. 11, pp. 4949-4956, 2000.

[85] A. Burman, S. Clark, N. G. A. Abrescia, E. E. Fry, D. I. Stuart, and T. Jackson, "Specificity of the VP1 GH loop of foot-and-mouth disease virus for $\alpha_{\mathrm{v}}$ integrins," Journal of Virology, vol. 80, no. 19, pp. 9798-9810, 2006.

[86] S. Kraft, B. Diefenbach, R. Mehta, A. Jonczyk, G. A. Luckenbach, and S. L. Goodman, "Definition of an unexpected ligand recognition motif for $\alpha_{\mathrm{v}} \beta_{6}$ integrin," The Journal of Biological Chemistry, vol. 274, no. 4, pp. 1979-1985, 1999.

[87] A. E. John, J. C. Luckett, A. L. Tatler et al., "Preclinical SPECT/CT imaging of $\alpha_{\mathrm{v}} \beta_{6}$ integrins for molecular stratification of idiopathic pulmonary fibrosis," The Journal of Nuclear Medicine, vol. 54, no. 12, pp. 2146-2152, 2013. 


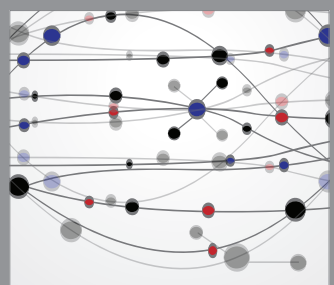

The Scientific World Journal
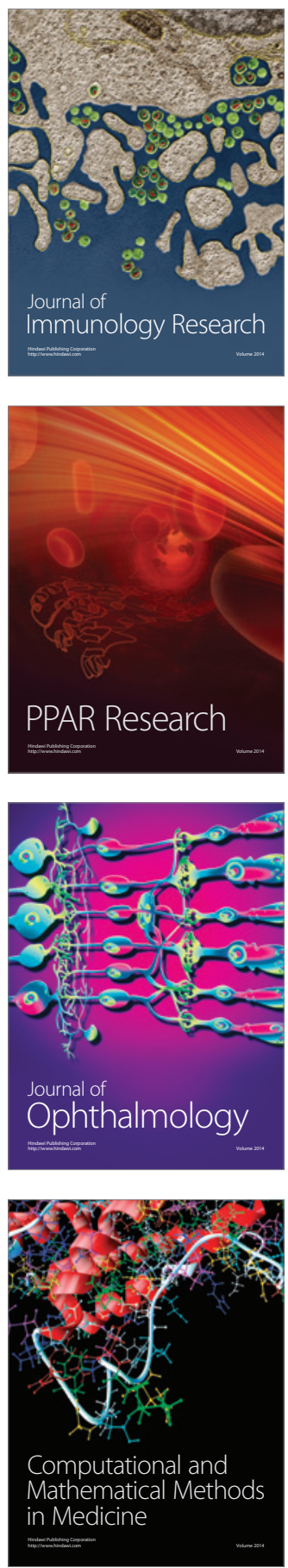

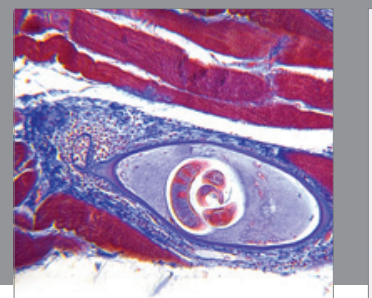

Gastroenterology

Research and Practice
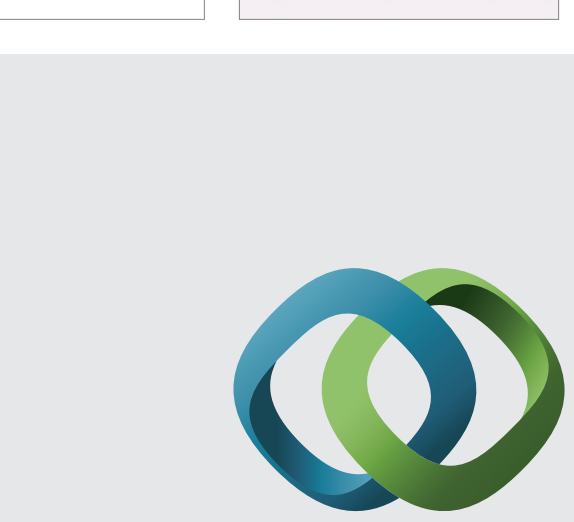

\section{Hindawi}

Submit your manuscripts at

http://www.hindawi.com
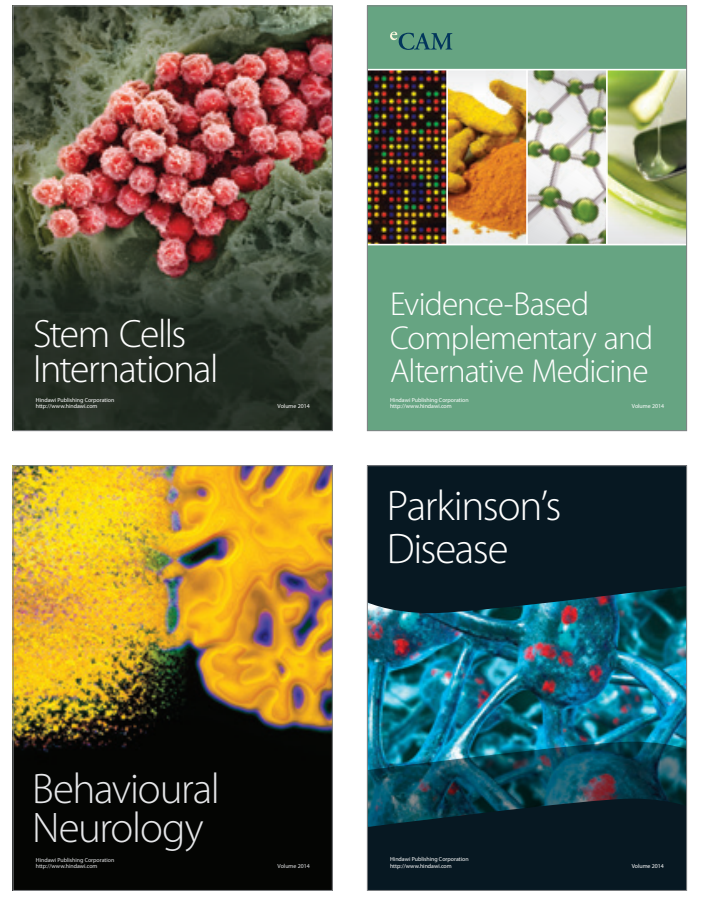
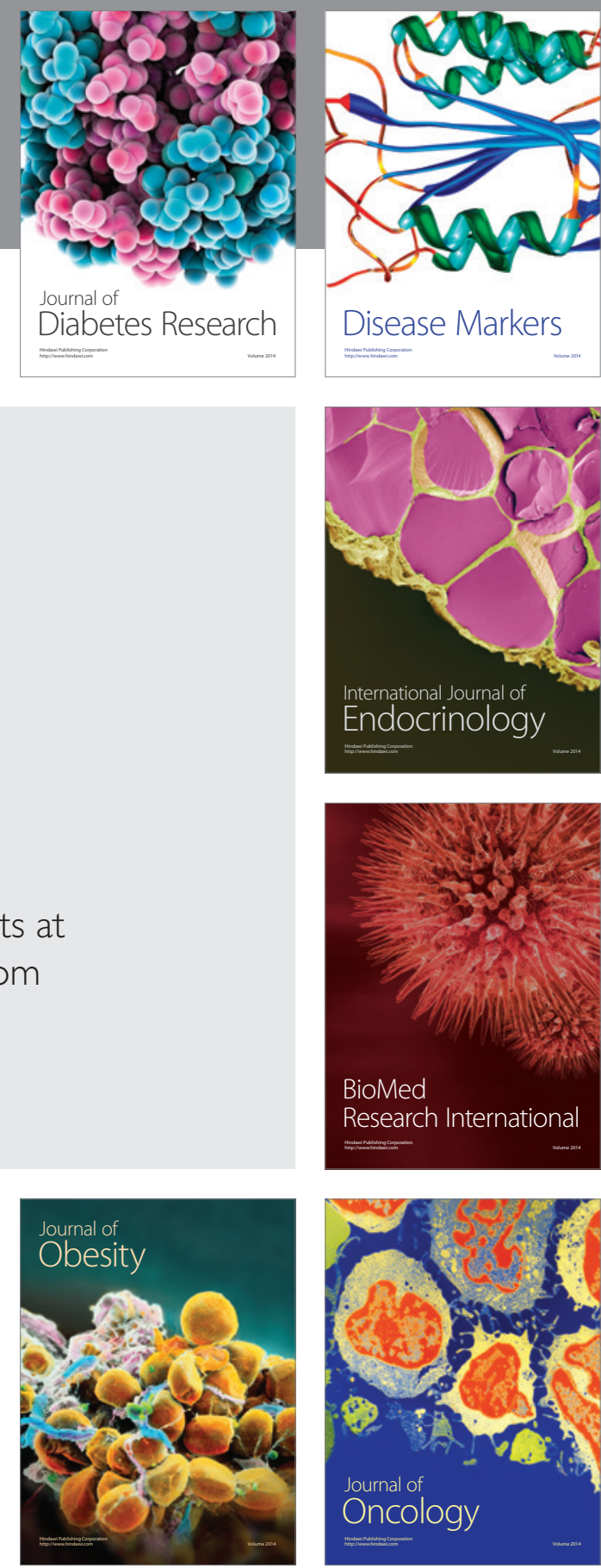

Disease Markers
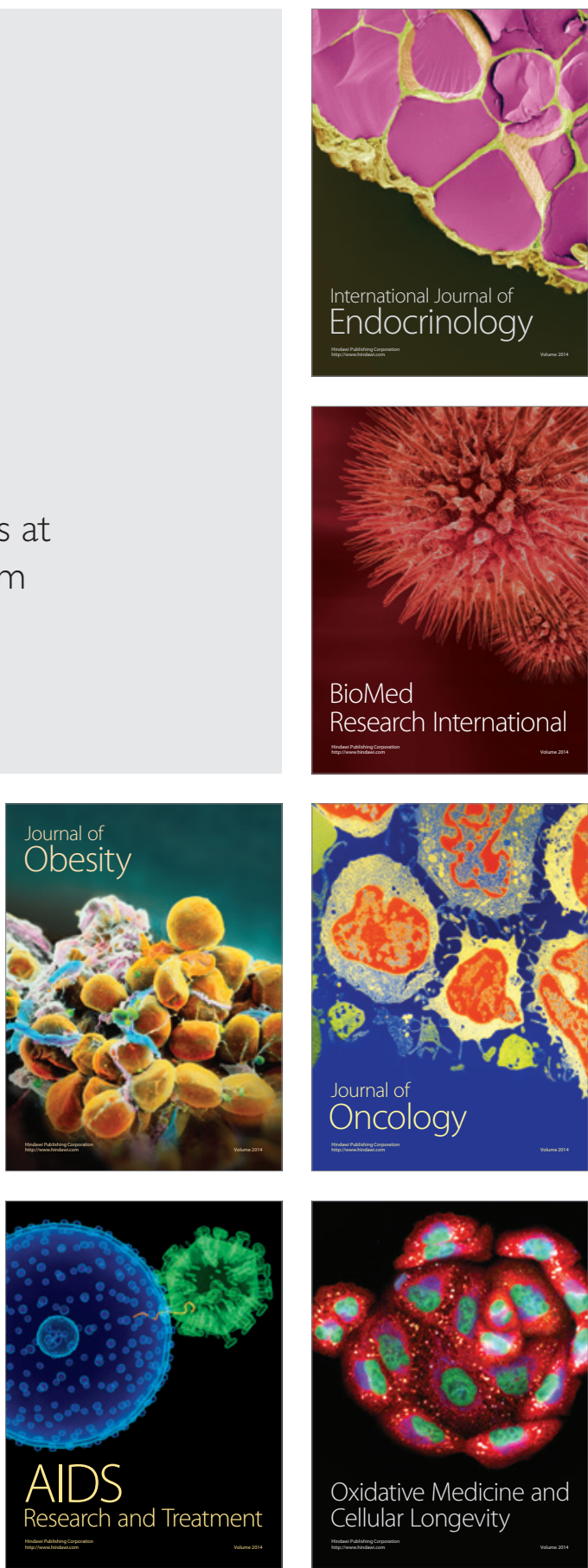